Review Article

\title{
Inflammation, HIV, and Immune Quiescence: Leveraging on Immunomodulatory Products to Reduce HIV Susceptibility
}

\author{
Ross Cromarty $\mathbb{D i D}^{1}$ and Derseree Archary $\mathbb{D i D}^{1,2}$ \\ ${ }^{1}$ Centre for the AIDS Programme of Research in South Africa (CAPRISA), Nelson Mandela School of Medicine, \\ University of KwaZulu-Natal, Durban, South Africa \\ ${ }^{2}$ Department of Medical Microbiology, University of KwaZulu-Natal, Durban, South Africa \\ Correspondence should be addressed to Derseree Archary; desh.archary@caprisa.org
}

Received 18 June 2020; Revised 23 September 2020; Accepted 15 October 2020; Published 27 October 2020

Academic Editor: David Katzenstein

Copyright (C) 2020 Ross Cromarty and Derseree Archary. This is an open access article distributed under the Creative Commons Attribution License, which permits unrestricted use, distribution, and reproduction in any medium, provided the original work is properly cited.

\begin{abstract}
The relationship between inflammation and HIV has been a focus of research over the last decade. In HIV-infected individuals, increased HIV-associated immune activation significantly correlated to disease progression. While genital inflammation (GI) has been shown to significantly increase the risk of HIV acquisition and transmission, immune correlates for reduced risk remain limited. In certain HIV-exposed seronegative individuals, an immune quiescent phenotype characterized reduced risk. Immune quiescence is defined by specific, targeted, highly regulated immune responses that hinder overt inflammation or immune activation. Targeted management of inflammation, therefore, is a plausible strategy to mitigate HIV risk and slow disease progression. Nonsteroidal anti-inflammatory drugs (NSAIDs) such as hydroxychloroquine and aspirin have shown encouraging preliminary results in low-risk women by reducing systemic and genital immune activation. A topical NSAID, containing ibuprofen, is effective in treating vulvovaginal inflammation. Additionally, the glucocorticoids (GCs), prednisolone, and dexamethasone are used to treat HIV-associated immune activation. Collectively, these data inform on immune-modulating drugs to reduce HIV risk. However, the prolonged use of these pharmaceutical drugs is associated with adverse effects, both systemically and to a lesser extent topically. Natural products with their reduced side effects coupled with anti-inflammatory properties render them viable options. Lactic acid (LA) has immunomodulatory properties. LA regulates the genital microbiome by facilitating the growth of Lactobacillus species, while simultaneously limiting bacterial species that cause microbial dysbiosis and GI. Glycerol monolaurate, besides being anti-inflammatory, also inhibited SIV infections in rhesus macaques. The proposed pharmaceutical and natural products could be used in combination with either antiretrovirals for treatment or preexposure prophylaxis for HIV prevention. This review provides a summary on the associations between inflammation, HIV risk, and disease progression. Furthermore, we use the knowledge from immune quiescence to exploit the use of pharmaceutical and natural products as strategic interventions to manage inflammation, toward mitigating HIV infections.
\end{abstract}

\section{Introduction}

Human immunodeficiency virus (HIV), which causes acquired immunodeficiency syndrome (AIDS), is a global epidemic affecting approximately 37.9 (range 32.7-44) million people with an estimated 1.7 (range 1.4-2.3) million new infections for the year of 2018 [1]. Currently, subSaharan Africa (SSA) is the worst affected region with 20.6 (range 18.2-23.2) million infected individuals, with 800,000 new infections in the region during 2018 [1]. Furthermore, young women (15-24 years) are of particular concern in SSA as they account for over half of new HIV infections in this region [2]. The roll out of antiretroviral (ARV) drugs for infected populations has significantly altered the trajectory of the disease and the epidemic, transforming it into a manageable chronic condition for the majority of infected individuals [3]. The use of ARVs as preexposure prophylaxis (PrEP) for prevention has shown promise in men who have sex with men (MSM) populations taking oral PrEP [4-7]. However, variable degrees of success with oral PrEP have 
been found in heterosexual populations [8-11]. The use of PrEP topically, in formulations such as microbicides gels and vaginal rings among others, has also shown some promise $[12,13]$. However, despite the relative success of these PrEP trials, behavioral factors such as PrEP adherence [14] and biological factors such as genital inflammation [15] and a dysbiotic vaginal microbiome [16] have been shown to undermine these prevention strategies [17]. This review summarizes our current knowledge on the interplay between HIV and inflammation and the causes and consequences of inflammation. We also provide insight into immune quiescence as a protective factor against HIV acquisition with special emphasis on the putative use of pharmaceutical or natural products toward inducing a quiescent genital immune environment.

\section{Inflammation and HIV}

Inflammation has been associated with an increased risk of HIV transmission and acquisition [18-21]. In HIV-infected individuals, increased proinflammatory cytokine levels and immune activation directly correlated with increased HIV viral loads in genital secretions [20-23], thereby increasing the probability of onward transmission. Inflammatory cytokines, tumour necrosis factor- $\alpha$ (TNF- $\alpha$ ) and interleukin-1 (IL-1), were shown to directly affect HIV replication by activation of the NF- $\kappa \beta$ transcription factor, which binds to the HIV promoter region [24]. Furthermore, in a nonhuman primate (NHP) model of simian immunodeficiency virus (SIV) infection, higher monokine induced by interferon- $\gamma$ (MIG) and interferon- $\gamma$-induced protein 10 (IP-10) mRNA levels in lymph nodes were positively correlated with more rapid disease progression [25]. However, antibody blocking of MIG was shown to reduce HIV-1 replication in an ex vivo human cervical tissue model [26]. In women who were shedding HIV compared to those with undetectable HIV in the genital tract, increased concentrations of TNF- $\alpha$, IL- $1 \beta$, IL-6, and IL- 8 were found [27]. Furthermore, monocyte chemoattractant protein 1 (MCP-1) was reported to be positively correlated with viral loads and promoting X4tropic HIV infection of resting CD4+ T cells [28].

There are various mechanisms whereby inflammation creates a conducive environment for HIV acquisition. In HIV-uninfected individuals, inflammation resulted in recruitment of HIV target cells and epithelial barrier damage [29-31]. Moreover, immune activation and increased cytokine levels were directly associated with increased HIV acquisition risk in both the blood $[32,33]$ and the genital tract [19, 34]. Nazli et al. [35] demonstrated that mucosal epithelial cells secreted increased proinflammatory cytokines upon exposure to HIV-1. In addition, TNF- $\alpha$ and interferon- (IFN-) $\gamma$ have been implicated in reduced epithelial barrier function, thereby increasing permeability of the mucosal barrier [35-40]. Conversely, IL-17 seems to play a critical role in the maintenance of the mucosal barrier [41, 42]. Li et al. [43] described a process of target cell recruitment in rhesus macaques; macrophage inflammatory protein- (MIP-) $3 \alpha$ and IL-8 expression recruit plasmacytoid dendritic cells (pDCs) which in turn secrete MIP- $1 \alpha$ and
MIP- $1 \beta$, which recruit CCR5+ cells. Using an in vivo rhesus macaque model, they showed that inflammation and recruitment of target cells to the genital tract were important events for seeding and forming foci of SIV infection following vaginal challenge [43]. A study by Masson et al. [19] showed that elevated genital tract chemotactic cytokines MIP- $1 \alpha$, MIP-1 $\beta$, IL- 8 , and IP-10, which formed part of the definition for genital inflammation, conferred a more than three-fold increased risk for HIV acquisition [19]. Similarly, a follow-up study by Liebenberg et al. [18] comparing plasma and genital tract cytokine levels showed that increased mucosal concentrations of IP-10, MIP- $1 \beta$, IL-8, and monocyte chemoattractant protein- (MCP-) 1 were associated with increased HIV acquisition risk [18]. MIP- $3 \alpha$ and IL-8 are important chemokines that facilitate infection through their chemotactic activity involved in the recruitment of HIV target cells [44, 45]. Additionally, IP-10, MIP$1 \alpha$, and MIP- $1 \beta$ have also been shown to recruit HIV target cells [46-49]. The MIP- $1 \alpha$-CCR5 interaction was also shown to activate the JAK/STAT signalling pathway, which is also a key to initiating cellular proliferation [50] and the inflammatory cascade $[51,52]$.

\section{Causes of Genital Inflammation}

Various biological and behavioral factors have been implicated in causing inflammation in the genital tract. Biological factors include sexually transmitted infections (STIs) and a dysbiotic vaginal microbiome. Risk for HIV acquisition has been associated with preexisting STIs [53-55], likely due to the inflammatory and immune responses against the causative pathogens [56-58]. Furthermore, asymptomatic STIs can further exacerbate inflammation through elevated genital tract inflammatory cytokine profiles and increase the risk for HIV acquisition [59]. Common STIs associated with increased HIV acquisition risk include the herpes simplex virus (HSV) $[60,61]$, human papillomavirus (HPV) [62, 63], Neisseria gonorrhoeae [64], Chlamydia trachomatis [65], and Trichomonas vaginalis [66, 67].

A dysbiotic vaginal microbiome, commonly referred to as bacterial vaginosis (BV), occurs when there is a shift from a Lactobacillus dominant to a non-Lactobacillus dominant genital mucosal environment with highly diverse bacterial communities [68]. This dysbiosis often leads to an inflammatory response and subsequent increase in the permeability of the mucosal epithelia [69-71], thus increasing the risk of HIV acquisition [72-76]. Furthermore, a recent study demonstrated the efficacy of the topical 1\% tenofovir gel used in the CAPRISA 004 trial as PrEP was undermined in women who had a non-Lactobacillus-dominated microbiome [16]. This decreased efficacy was attributed to the direct metabolism of tenofovir (TFV) by Gardnerella vaginalis in women with a non-Lactobacillus-dominated vaginal microbiome [16, 77].

Vaginal practices have been noted in certain populations of women, which include practices for intimate female hygiene [78] and to enhance sexual pleasure [79]. These practices include washing, douching, and insertion of products, among others [80]. While no studies have been 
powered to investigate the link between vaginal practices and HIV risk, there is biological plausibility [81]. Studies have shown that women who practice various forms of vaginal hygiene may impact the vaginal microflora $[82,83]$, which could lead to a dysbiotic microbiome $[84,85]$ and a subsequent inflammatory response in the genital tract $[69,70,86]$. Furthermore, although there is no direct evidence, inserting products into the vaginal tract is likely to compromise the mucosal barrier through causing microabrasions for easier HIV viral translocation.

Together, STIs, a dysbiotic vaginal microbiome, and vaginal practices have been shown as major factors driving inflammation in the female reproductive tract (FRT). However, these factors alone are not solely responsible for causing genital inflammation, and further studies are warranted to define the complex immunology of this vulnerable site.

\section{HIV-Exposed Seronegative (HESN)}

The risk of HIV infection is heterogenous across a population. Individuals that are continually exposed to HIV without becoming productively infected over a long period of observation are called HIV-exposed seronegative (HESN). HESN individuals display particular immunological phenotypes that have been posited as immune correlates of protection against HIV [87-89]. Genetic polymorphisms, such as mutations in the KIR, HLA, CCR2, CCR5, IRF-3, and CCL3 genes, conferred a significant protection against HIV in certain HESN individuals [90-95]. One particular genetic polymorphism was the delta 32 mutation in the CCR5 encoding region in the genome [96-98]. Other correlates of protection discovered were the presence or induction of particular immune responses [99] of both innate [100-104] and adaptive immunity [105-109], that were able to control acute infection by either neutralizing the virus [110-112] or killing infected cells [113-115] before the formation of foci or viral propagation could occur. An additional correlate for reduced HIV susceptibility in vitro showed significantly greater sterol metabolism, possibility related to the induction of type-1 interferon genes, in peripheral blood mononuclear cells (PBMCs) from HESN individuals compared to healthy controls [116]. These types of immune responses, which are generally triggered through toll-like receptor (TLR) signalling [117], have increased the interest in using TLR agonists as adjuvants in vaccine research $[118,119]$ including HIV. However, it should be noted that there is heterogeneity between HESN populations as they do not display the same immune correlates of protection, which makes the comparisons across studies difficult. A particular cohort of HESN commercial sex workers (CSWs) from the Pumwani district in Nairobi, Kenya, has been followed and studied extensively since 1984 [120]. Reduced immune activation and inflammation, commonly termed as immune quiescence, was identified in this group of HESNs. The concept of immune quiescence as a correlate of protection for HIV acquisition has largely stemmed from biological and behavioral studies on this particular cohort.

\section{Immune Quiescence and HIV Risk}

The concept of immune quiescence is not only unique in HESNs but has also been observed in sooty mangabeys, the natural host for SIV. Despite these animals being infected with SIV, with high levels of viral replication and depletion of gut CD4+ T cells, sooty mangabeys do not progress to AIDS [121]. Lower levels of systemic and mucosal CD4+CCR5+ T cells [122], reduced type 1 IFN responses [123], lower Th17 cell numbers [124], and better management of immune activation through IL-10 and regulatory T cell (Treg) upregulation [121] attributed to their quiescent state despite ongoing SIV replication and high viral loads.

Multiple studies have reported reduced immune activation in HESN individuals $[89,104,125-128]$ underscoring the importance of modulating inflammation and immune activation or having an immune quiescent environment in an effort to minimize the risk of acquiring HIV. Reduced immune activation, defined by lower CD69 expression on $\mathrm{CD} 4+$ and CD8+ $\mathrm{T}$ cells, was found to be a correlate of protection in HESN CSWs compared to HIV-uninfected CSWs. In addition, the reduced immune activation was associated with increased frequencies of regulatory $\mathrm{T}$ cells $[129,130]$. Furthermore, low frequencies of CD4+ and CD8+ T cells expressing HLA-DR, CD38, CD70, and Ki67 were reported in a MSM HESN cohort [131]. Similarly, the uninfected partners of serodiscordant couples had reduced expression of the activation markers CD38, HLA-DR, and CCR5 on CD4+ T cells $[132,133]$, the target cells for HIV infection. Together, these studies reinforce the concept that lower levels of immune activation are associated with reduced HIV acquisition risk. Our in vitro data show that PBMCs stimulated with lipopolysaccharide (LPS) were less susceptible to HIV infection than the unstimulated negative control [134]. LPS stimulation elicited a strong cytokine response with very limited immune activation (defined by CD38 and HLA-DR expression on CD4+ and CD8+ T cells) [134], partially reminiscent of an immune quiescent environment. These data highlight the potential of TLR agonists to induce protective immune responses; however, the continued management of these immune responses will be necessary to avoid overt inflammation.

Furthermore, molecular studies investigating the function of CD4+ T cells from HESN CSWs found lower levels of gene expression in PBMCs and whole blood compared to HIV-uninfected susceptible CSWs [127, 135]. The most under expressed genes identified in HESN CSWs were involved in T cell receptor signalling and host factors required for HIV replication [127, 135]. Despite the difference in cytokine levels being lost after stimulation, unstimulated PBMCs from HESN CSWs were shown to produce lower levels of cytokines compared to PBMCs from HIV-uninfected HESN [127]. This suggests that PBMCs from HESN CSWs are not immunosuppressed, but rather have lower baseline expression of cytokines. Similarly, even after PBMC stimulation, lower levels of IL-17 and IL-22 were still observed in HESN CSWs, suggesting that HESN individuals have a blunted Th17 response [125]. Th17 cells are an important subset of CD4+ T cells and play an important role in 
homeostasis of mucosal tissues [136-138]. However, despite Th17 cells being essential for mucosal barrier integrity, they are preferentially hijacked for HIV infection $[41,139]$. The duality of Th17 cells has been shown to be an important target and is particularly susceptible to infection in a SIV NHP model [140, 141], while remaining susceptible to preferential depletion in HIV-infected individuals $[142,143]$.

As the majority of HIV infections occur at the FRT, the immune environment within this compartment will be important in determining HIV risk. In the study by Chege et al. [125], cervical mononuclear cells (CMCs) expressed lower IL-17 and IL-22 after stimulation, suggesting that a blunted Th17 response [125] may be protective against HIV infection. Furthermore, reduced expression of pattern recognition receptors (PRRs), and low cytokine production in culture was reported in HESN CMCs [104]. Despite this, these CMCs produced strong antiviral responses after TLR7/ 8 stimulation, suggesting that cells with immune quiescent phenotypes from HESNs can still elicit protective antiviral responses against HIV [104]. Lajoie et al. [89] investigated differences between HESN CSWs, HIV-infected CSWs, and HIV-uninfected CSWs and found that HESN individuals had lower expression levels of the proinflammatory cytokine IL- $1 \alpha$ and IFN- $\gamma$-regulated chemokines MIG and IP- 10 . Furthermore, the reduced cytokine expression correlated with higher levels of mucosal antiproteases in HESN individuals, suggesting unique expression patterns of mucosal immune mediators, which create an environment less conducive to HIV acquisition [89]. Additionally, MIG and IP-10 bind to CXCR3, which induces the recruitment of activated T cells [89], suggesting that these two chemokines play an important role in modifying HIV risk. These studies describe immune quiescence in the mucosal compartment, which leads to reduced recruitment of HIV target cells, and hence, a reduced risk for HIV infection. Therefore, inducing an immune quiescent mucosal environment is a biologically plausible strategy to reduce risk of HIV infection. We suggest that the use of immunomodulatory products, possibly in combination with ARVs after thorough and rigorous scientific and clinical trial testing, may be an additional strategy to incorporate into the currently limited HIV prevention options.

\section{Immunomodulatory Products}

Since genital inflammation is regarded as a significant risk factor for HIV infection and immune quiescence was attributed as a correlate of protection in certain populations, products that modulate inflammation are attractive additive HIV prevention options. Increased comorbidities in HIVinfected individuals $[144,145]$ warrant the use of anti-inflammatory therapies to stem HIV-associated inflammation and immune activation [146-150] to ameliorate disease.

6.1. Antiretroviral Drugs. Interestingly, ARVs have been associated with reduced immune activation. In a rhesus macaque model of rectal simian human immunodeficiency virus (SHIV) infection, monkeys that were given oral PrEP had reduced levels of cytokines: IL-15, IL-18, and IL-RA [151]. Healthy human participants taking daily PrEP for 30 days had lower systemic CD8 T cell activation (CD38/HLADR coexpression) compared to their baseline before PrEP initiation; however, cytokines and other markers of inflammation in the blood were not affected [152]. In high-risk heterosexual HIV serodiscordant African couples, daily oral PrEP also did not modulate HIV-specific immune responses [153]. There may, however, be a heterogenous effect of ARVs on immunity depending on exposure to HIV or HIV infection itself.

6.2. Nonsteroidal Anti-Inflammatory Drugs. Nonsteroidal anti-inflammatory drugs (NSAIDs) are the most common anti-inflammatory drugs prescribed for reducing inflammation and through this process, suppress pain [154]. NSAIDs account for approximately $5-10 \%$ of prescribed medication each year [155]. The main mechanism for NSAIDs is through the inhibition of the cyclooxygenase (COX) enzymes, which convert arachidonic acid into prostaglandins [156]. Prostaglandins in turn exhibit varied and seemingly opposite functions such as induction and resolution of inflammation [157]. In the following sections, we discuss some commonly used NSAIDs that are used to treat inflammation.

6.3. Aspirin. Acetylsalicylic acid (ASA), commonly known as Aspirin ${ }^{\circledR}$, is a very common NSAID with fairly good safety profiles [158]. Aspirin ${ }^{\circledR}$ is Food and Drug Administration (FDA) in the United States of America approved and is also readily available as an over-the-counter drug. ASA is commonly used to treat headaches [159], to prevent cardiovascular disease [160-162], and to reduce the risk of breast [163] and colorectal cancer [164].

A study of daily oral Aspirin ${ }^{\circledR}$ in low-risk Kenyan women found reduced levels of systemic and mucosal HIV target CD4+ T cells and Th17 cells and reduced systemic inflammatory cytokines [165]. Even in HIV-infected virologically suppressed patients, low-dose Aspirin ${ }^{\circledR}$ was shown to reduce platelet count, $\mathrm{T}$ cell, and monocyte activation [166], thereby reducing the risk of non-AIDS-related morbidities, such as cardiovascular diseases [144].

6.4. Ibuprofen. Ibuprofen (IBF) is a frequently prescribed and commonly used NSAID with prominent analgesic and antipyretic properties $[167,168]$. IBF has similar efficacies as ASA for the treatment of conditions such as headaches [169]. Furthermore, IBF is used for the treatment of various inflammatory, musculoskeletal, and rheumatic disorders [170]. IBF has also been shown to increase the efficacy of nucleoside reverse transcriptase inhibitors (NRTI) by reducing drug transporter proteins, thus limiting the transport of NRTI's out of the cells [171, 172]. IBF is available commercially as a topical anti-inflammatory (Ginenorm ${ }^{\circledR}$ (ibuprofen isobutanolammonium)) as is a vaginal douche. Ginenorm ${ }^{\circledR}$ is effective for treating the inflammatory 
condition vulvovaginitis and has a superior action compared to other NSAID topical options such as benzydamine [173].

6.5. Indomethacin. The NSAID indomethacin is primarily used not only for the treatment of rheumatoid arthritis but also limits HIV replication $[174,175]$. In the presence of indomethacin, but not other NSAIDS (Aspirin ${ }^{\circledR}$, indoprofen, IBF, or naproxen), MT-4 cells (CD4+ T cell line) displayed reduced HIV replication, measured by ELISA as reduced p24 production [174]. Furthermore, indomethacin suppressed HIV replication further when used in combination with an antiviral plant protein called MAP30 [175]. Additionally, similar to IBF, indomethacin improved NRTI efficacy by reducing drug transporter proteins, thus reducing the efflux of these drugs out of cells $[171,172]$.

6.6. Chloroquine and Hydroxychloroquine. The use of chloroquine (CQ) and hydroxychloroquine (HCQ) have been investigated fairly extensively in HIV-infected populations as well. Both of these drugs, taken orally, have been shown to significantly reduce HIV-associated immune activation [147-150]. Furthermore, chloroquine was also shown to directly limit HIV replication and DC-SIGNmediated HIV viral transfer to CD4+ T cells both in vitro and in vivo [176].

Daily HCQ use was shown to reduce the numbers of circulating CD4+ CCR5+ and Th17 cells, while mucosal Th17 cells expressed lower immune activation markers CCR5 and CD69 [165]. Oral HCQ administration reduced systemic, but not mucosal, IP-10, and IL-2RA [165]. Furthermore, an HCQ vaginal implant was tested in a rabbit and mouse model, and its immunomodulatory effects were tested in the presence of nonoxynol-9- (N9-) induced inflammation. N9, originally designed as a spermicide, was also hypothesized to reduce HIV infection through disrupting the HIV viral membrane. However, N9 increased HIV risk by causing inflammation [177-179]. In contrast, the HCQ implant alone was able to reduce the recruitment of immune cells, improve mucosal epithelial integrity, reduce $\mathrm{T}$ cell activation, and reduce inflammatory cytokine production [180] suggesting that an implant containing an antiinflammatory drug may reduce the risk of HIV infection.

6.7. Glucocorticoids. Glucocorticoids (GCs) are also commonly referred to as corticosteroids, although technically GCs are part of the corticosteroid class of drugs. GCs are produced endogenously in the adrenal glands and other tissues [181] as hormonal compounds and are essential to everyday life to regulate and support the physiological process throughout the body [182]. GCs modulate immunity through the interference of gene transcription, resulting in impaired signalling pathways $[183,184]$, and through nongenomic effects such as interactions with cellular membranes and receptors to initiate or inhibit signalling responses [185]. GCs have also been shown to induce apoptosis of T cells [186], a potential mechanism for immunomodulation. A major hallmark of AIDS is the steady decline in the numbers of CD4+ T cells through a combination of cellular apoptosis, exhaustion, and subsequent immune system dysfunction [187]. Triggering of the GCinduced tumour necrosis factor receptor family-related (GITR) protein has been shown to limit $\mathrm{T}$ cell apoptosis, thereby improving immune function, measured by cytokine expression [188], highlighting the potential of GCs to slow HIV disease progression by limiting CD4+ T cell loss. In the following sections, we discuss some commonly used GCs that are used to treat inflammation.

6.8. Dexamethasone. Dexamethasone (DEX) is a commonly used GC. DEX has been shown to reduce cytokines associated with a $\mathrm{TH} 1$ response, with concomitant increase of cytokines associated with a Th2 response in human PBMCs [189]. Apart from the traditional GC effects on gene transcription, DEX has additional posttranscriptional regulatory effects [190, 191], enhancing its immunomodulatory effects. Furthermore, DEX has also been shown to reduce arachidonic acid derived from the cellular membranes of epithelial cells [192] and suppression of COX-2 and prostaglandin E2 expression [193], highlighting the additional immunomodulatory effects of this drug. Similar to indomethacin, DEX has shown to inhibit HIV replication in an MT-4 cell line, an effect potentiated by concurrent MAP30 treatment [175]. DEX also suppressed the HIV promoter region, thus inhibiting viral transcription and subsequent replication [194]. However, DEX inhibited the killing of HIV-infected CD4+ T cells by macrophages, mediated through antibodydependent cellular cytotoxicity, in PBMCs from both HIVinfected and uninfected individuals [195], highlighting that DEX, and likely most GCs, can be overtly immunosuppressive and dampen protective responses too.

6.9. Betamethasone. Betamethasone (BMS) is another common GC, which is similar to DEX. BMS is commonly used topically, and these topical formulations have been around for years [196]. In a mouse model, topical BMS reduced the expression of IFN- $\gamma$, IL- $1 \beta$, TNF- $\alpha$, IL-17, IL-22, and IL-13 induced by TLR7/8 stimulation [197]. Similarly, a topical beclomethasone dipropionate inhibited allergeninduced T cell production of IL-3, IL-5, and GM-CSF [198]. Data from our group shows that BMS was potently immunosuppressive in human PBMCs stimulated with TLR agonists LPS, R848, and Pam3CSK4 and the mitogen PHA and even in our unstimulated condition [199]. Furthermore, despite global immunosuppression, BMS significantly reduced HIV-infected CD4+ T cells in the unstimulated and LPS-stimulated conditions, but not in R848, Pam3CSK4, or the PHA conditions [199]. These results suggest that it may be prudent to understand the inflammatory response at the gene transcription level to identify potential drug targets, which lead to the discovery and formulation of appropriate drugs.

6.10. Prednisolone. Prednisolone, another common GC, has been used extensively in reducing HIV-associated immune 
activation to slow the progression to AIDS [200]. The use of prednisolone has been shown to reduce HIV viral loads, chemokine MCP-1 [201], and HIV-associated immune activation [202]. Furthermore, prednisolone slows the loss of CD4+ T cells and inhibits apoptosis of activated CD4+ T cells in ARV-treated patients and during structured therapy interruption [203-205], hindering the progression to AIDS. Conversely, prednisolone treatment in HIV-infected ARV treatment naïve patients showed no effect on disease progression with continued high viral loads despite reduced immune activation, likely due to increased target CD4+ T cells supporting ongoing viral replication [206].

\section{Natural Compounds}

Anti-inflammatory drugs do have unwanted and off-target adverse effects [207, 208]. Chronic use of NSAIDs has adverse effects on the gastrointestinal tract $[209,210]$, the kidney [211], and the cardiovascular system [212]. Similarly, chronic GC use can increase the risk for cardiovascular $[213,214]$ and metabolic diseases [215] and neurodegeneration [216]. Although, topical NSAID and GC treatments have dramatically less common adverse effects, systemic effects have been reported with continued use [217, 218], especially in elderly patients [219]. Mucosal surfaces being more permeable than skin are especially susceptible to potential adverse events [220]. Therefore, natural products that may have minimal, if any side effects, either in combination or alone may provide an alternative for certain indications. Three such products are discussed as follows as these have already been formulated for topical use and have shown promising results from in vitro and animal studies.

7.1. Vitamin D. Vitamin D deficiency has been associated with a myriad of diseases such as cardiovascular disease, cancers, chronic lung disease, diabetes, and autoimmune diseases in addition to its well-known role in reduced bone homeostasis [221, 222]. Vitamin D has numerous physiological effects on the immune system [223] as its primary active metabolite is a steroid hormone [224]. Supplementation with the active compound of vitamin $\mathrm{D}$, calcitriol, has proven to be effective in preventing both the initiation and progression of various autoimmune diseases in humanized mice models [225-227]. Vitamin D is available as a topical formulation to treat psoriasis [228]. Vitamin D analogues are known to upregulate Th2 and Treg responses and may counter balance against the adverse effects of GCs [229], which cause global immunosuppression. Combination therapies utilising BMS and another vitamin D analogue, calcipotriol (CAL), were shown to be highly and more effective for treating psoriasis than BMS monotherapy alone [230].

Patients with vitamin $\mathrm{D}$ deficiency display a similar immune dysfunction profile to that of HIV-infected patients. A hallmark of HIV disease progression is dysregulated immune activation [231]. Since vitamin D has immunoregulatory properties [223], vitamin D supplementation may be a suitable adjunctive therapy to slow disease progression and possibly lower inflammation and immune activation to limit HIV replication. A clinical trial (http://clinicaltrials.gov identifier NCT03426592) is currently in progress to assess the impact of vitamin D supplementation on HIV latency. Furthermore, the association between the use of certain ARVs and reduced vitamin D levels [231] highlights the need for further studies to identify mechanisms for vitamin D depletion in HIV-infected populations on ARVs. These data may be important at a public health level for vitamin $\mathrm{D}$ supplementation into ARV regimens in HIV endemic populations.

7.2. Glycerol Monolaurate. The most successful non-ARVbased microbicide is glycerol monolaurate (GML), which is also commonly used in cosmetic products. Two studies in SIV rhesus macaque models demonstrate the effect of GML in preventing SIV infection $[43,232]$. Two mechanisms of action were identified; first, GML is a fatty acid monoester, which assists with membrane stabilization by blocking bacterial-induced pore formation and $\mathrm{T}$ cell activation [233-236]. Second, GML disrupts $\mathrm{T}$ cell signalling and function [237] and inhibits cytokine and chemokine production, thereby preventing the recruitment and activation of HIV target cells and important preceding events for establishment of SIV infection [43]. Furthermore, GML was shown to inhibit Candida and Gardnerella vaginalis in women [238]; the overgrowth of these two microbes is associated with BV [68] and subsequent inflammation of the genital tract $[56,69,70]$. Additionally, GML had no impact on the Lactobacilli sp. [238], the bacterial species generally associated with a healthy vaginal microbiome [68]. GML also inactivates HSV-2 [239] and Chlamydia trachomatis [240]. GML with its low side effects profile and its ability, at least in preclinical studies, to prevent SIV infections, is an attractive candidate for topical formulation as an HIV prevention modality.

7.3. Lactic Acid. Lactic acid (LA) is a naturally occurring compound commonly found in the female genital tract that is produced by Lactobacillus species [241, 242]. The amount of LA depends on the dominance of the Lactobacillus species. A vaginal microbiome that is dominated by Lactobacillus species, with low abundance of microbial diversity, is often termed a "healthy" vaginal microbiome [243]. Research has been focussed on the role that LA plays in the female reproductive tract. Both the $\mathrm{L}$ and $\mathrm{D}$ isomers of LA have potent anti-inflammatory effects. Both isomers suppressed the expression of inflammatory cytokines IL$1 \beta$, IL-6, IL-8, TNF- $\alpha$, RANTES, and MIP-3 $\alpha$ [244]. Simultaneously, increased expression of the anti-inflammatory cytokine IL-1RA from cervicovaginal epithelial cells was observed, even in the presence of TLR stimulation and seminal plasma [244]. Furthermore, LA has been shown to inactivate HIV in vitro, with the L-isoform more potent than the $\mathrm{D}$-isoform, with this effect not solely due to $\mathrm{pH}$ [245]. Similarly, this antiviral effect of LA has been shown from clinical samples, whereby cervicovaginal fluid 
from women with Lactobacillus-dominated microbiomes was shown to inactivate HIV ex vivo [246].

Furthermore, topical LA is versatile and is used for the treatment of various skin and oral complications such as acne vulgaris, melanogenesis, and recurrent aphthous ulcerations, respectively [247-250]. An over-the-counter LA containing vaginal douche was assessed for its impact on vaginal microbiota, with adverse findings of 2.6 fold increased risk for acquiring diverse vaginal microbial species through douching with this product during menses [251]. However, the diverse and dysbiotic vaginal microbiome may arise through a combination of douching [83] and menses [252] and may not be the effect of LA itself, as the majority of the women in this study had a Lactobacillus-dominant vaginal microbiome at the start of the study [251]. An LAbased vaginal gel is also currently under investigation for its effectiveness in treating BV compared to the current standard-of-care, metronidazole [253]. As there is a high recurrence rate of $\mathrm{BV}$ after metronidazole treatment, a Lactobacillus crispatus containing vaginal gel used after metronidazole treatment was effective in preventing $\mathrm{BV}$ recurrence [254].

7.4. Alternative Natural Products. There are many other natural products that could be considered as possible adjunctive therapy due to their anti-inflammatory effects. Curcumin, a curcuminoid contained in turmeric, is one such natural product. Curcumin has shown potent anti-inflammatory and antimicrobial effects [255-258] and antiviral activity against HIV-1 and HSV-2 [258, 259]. Garlic is another such product that has been shown to display antiinflammatory effects [260-262]. Similarly, consistent with the growing global acknowledgment of medicinal properties of cannabis [263-265], this plant has been shown to have anti-inflammatory properties [266], mainly attributed to the cannabinoid metabolites contained within the plant [264, 267-270]. Cannabis was found to reduce the level of circulating CD16+ monocytes and levels of IP-10, compared to individuals who did not use cannabis [271]. Similarly, heavy cannabis use in HIV-infected individuals was associated with reduced frequencies of activated $\mathrm{CD} 4+$ and $\mathrm{CD} 8+\mathrm{T}$ cells and intermediate and nonclassical monocytes and cytokine producing antigen presenting cells [272], highlighting the immunomodulatory potential of cannabis in preventing inflammation and immune activation. As attractive as these products may be in modulating inflammation (based largely on in vitro data), their safety and side effects have to be rigorously, scientifically tested.

\section{Conclusion}

Genital inflammation significantly modifies the risk for HIV acquisition, although the causes of genital inflammation and exact biological mechanisms need to be further defined. Inflammation leads to the recruitment and activation of CD4+ T cells, which serve as target cells for HIV infection, with a concomitant disruption of the mucosal barrier allowing for easier viral translocation. HIV replicates more efficiently in activated target cells. Conversely, in the era preceding ARVs and PrEP, immune quiescence has been identified as an immune correlate of protection against HIV infection in some high-risk populations. The use of antiinflammatories to reduce HIV transmission is therefore not a new concept. Dampening inflammation to induce an immune quiescent phenotype in high-risk populations is attractive as adjunctive therapy in combination with PrEP or in areas where PrEP access is limited. Therefore, the purpose of this review was to highlight the associations between inflammation and increased HIV risk and immune quiescence and HIV and to propose products that may be used to induce immune quiescence to reduce the risk of HIV acquisition. Many pharmaceutical anti-inflammatory drugs have known adverse effects; therefore, we also proposed natural products that may be used either in combination or alone to mitigate HIV risk by reducing genital inflammation. However, inflammation is a necessary and protective response against invading pathogens and damaged tissues. The modulation of specific immune responses that initiate and drive the inflammatory cascade may be a key in preserving a certain threshold of inflammation that is protective. Therefore, interrogating the cellular transcriptional signalling pathways during inflammation will be an important first step in understanding which immunomodulatory products would be appropriate to use to mitigate overt inflammation, while allowing protective inflammatory responses to continue.

\section{Conflicts of Interest}

The authors declare that they have no conflicts of interest.

\section{Acknowledgments}

RC was supported by the National Institute of Health/National Institute of Allergy and Infectious Diseases (NIH/ NIAID) R01 (grant no. 1R01AI111936-01) and the CAPRISA Research Administration and Management Training Program (grant no. G11 TW010555-01). DA was supported through the Medical Research Council of South Africa SelfInitiated Grant (MRC SIR), the National Research Foundation (NRF) of South Africa, Thuthuka (grant no. TTK160517165310), the NRF Research Career Advancement Fellowship (grant no. RCA13101656388), and a senior fellowship through the European and Developing Countries Clinical Trials Partnership (EDCTP) (grant no. TMA2017SF-1960) funds.

\section{References}

[1] UNAIDS, Facts Sheet, UNAIDS, Geneva, Switzerland, 2019.

[2] UNAIDS, AIDSinfo Map, UNAIDS, Geneva, Switzerland, 2019, http://aidsinfo.unaids.org/.

[3] S. G. Deeks, S. R. Lewin, and D. V. Havlir, "The end of aids: HIV infection as a chronic disease," The Lancet, vol. 382, no. 9903, pp. 1525-1533, 2013.

[4] X. Huang, J. Hou, A. Song et al., "Efficacy and safety of oral TDF-based pre-exposure prophylaxis for men who have sex 
with men: a systematic review and meta-analysis," Frontiers in Pharmacology, vol. 9, p. 799, 2018.

[5] R. M. Grant, J. R. Lama, P. L. Anderson et al., "Preexposure chemoprophylaxis for HIV prevention in men who have sex with men," New England Journal of Medicine, vol. 363, no. 27, pp. 2587-2599, 2010.

[6] S. Mccormack, D. T. Dunn, M. Desai et al., "Pre-exposure prophylaxis to prevent the acquisition of HIV-1 infection (proud): effectiveness results from the pilot phase of a pragmatic open-label randomised trial," The Lancet, vol. 387, no. 10013, pp. 53-60, 2016.

[7] J.-M. Molina, C. Capitant, B. Spire et al., "On-demand preexposure prophylaxis in men at high risk for HIV-1 infection," New England Journal of Medicine, vol. 373, no. 23, pp. 2237-2246, 2015.

[8] L. Van Damme, A. Corneli, K. Ahmed et al., "Preexposure prophylaxis for HIV infection among African women," New England Journal of Medicine, vol. 367, no. 5, pp. 411-422, 2012.

[9] J. M. Marrazzo, G. Ramjee, B. A. Richardson et al., "Tenofovir-based preexposure prophylaxis for HIV infection among African women," New England Journal of Medicine, vol. 372, no. 6, pp. 509-518, 2015.

[10] J. M. Baeten, D. Donnell, P. Ndase et al., "Antiretroviral prophylaxis for HIV prevention in heterosexual men and women," New England Journal of Medicine, vol. 367, no. 5, pp. 399-410, 2012.

[11] M. C. Thigpen, P. M. Kebaabetswe, L. A. Paxton et al., "Antiretroviral preexposure prophylaxis for heterosexual HIV transmission in Botswana," New England Journal of Medicine, vol. 367, no. 5, pp. 423-434, 2012.

[12] Q. Abdool Karim, S. S. Abdool Karim, J. A. Frohlich et al., "Effectiveness and safety of tenofovir gel, an antiretroviral microbicide, for the prevention of HIV infection in women," Science, vol. 329, no. 5996, pp. 1168-1174, 2010.

[13] J. M. Baeten, T. Palanee-Phillips, E. R. Brown et al., "Use of a vaginal ring containing dapivirine for HIV-1 prevention in women," New England Journal of Medicine, vol. 375, no. 22, pp. 2121-2132, 2016.

[14] L. J. Koenig, C. Lyles, and D. K. Smith, "Adherence to antiretroviral medications for HIV pre-exposure prophylaxis: lessons learned from trials and treatment studies," American Journal of Preventive Medicine, vol. 44, no. 1, pp. s91-S98, 2013.

[15] L. R. Mckinnon, L. J. Liebenberg, N. Yende-Zuma et al., "Genital inflammation undermines the effectiveness of tenofovir gel in preventing HIV acquisition in women," Nature Medicine, vol. 24, no. 4, pp. 491-496, 2018.

[16] N. R. Klatt, R. Cheu, K. Birse et al., "Vaginal bacteria modify HIV tenofovir microbicide efficacy in african women," Science, vol. 356, no. 6341, pp. 938-945, 2017.

[17] A. Van der Straten, L. Van Damme, J. E. Haberer, and D. R. Bangsberg, "Unraveling the divergent results of preexposure prophylaxis trials for HIV prevention," AIDS, vol. 26, no. 7, pp. f13-F19, 2012.

[18] L. J. P. Liebenberg, L. Masson, K. B. Arnold et al., "Genitalsystemic chemokine gradients and the risk of HIV acquisition in women," JAIDS Journal of Acquired Immune Deficiency Syndromes, vol. 74, no. 3, pp. 318-325, 2017.

[19] L. Masson, J.-A. S. Passmore, L. J. Liebenberg et al., "Genital inflammation and the risk of HIV acquisition in women," Clinical Infectious Diseases, vol. 61, no. 2, pp. 260-269, 2015.

[20] A. J. Olivier, L. Masson, K. Ronacher et al., "Distinct cytokine patterns in semen influence local HIV shedding and HIV target cell activation," The Journal of Infectious Diseases, vol. 209, no. 8, pp. 1174-1184, 2014.

[21] H. B. Jaspan, L. Liebenberg, W. Hanekom et al., "Immune activation in the female genital tract during HIV infection predicts mucosal cd4 depletion and HIV shedding," The Journal of Infectious Diseases, vol. 204, no. 10, pp. 1550-1556, 2011.

[22] S. Gianella, M. C. Strain, S. E. Rought et al., "Associations between virologic and immunologic dynamics in blood and in the male genital tract," Journal of Virology, vol. 86, no. 3, pp. 1307-1315, 2012.

[23] P. M. Sheth, A. Danesh, K. Shahabi et al., "HIV-specific CD8+ lymphocytes in semen are not associated with reduced HIV shedding," The Journal of Immunology, vol. 175, no. 7, pp. 4789-4796, 2005.

[24] L. Osborn, S. Kunkel, and G. J. Nabel, “Tumor necrosis factor alpha and interleukin 1 stimulate the human immunodeficiency virus enhancer by activation of the nuclear factor kappa B," Proceedings of the National Academy of Sciences, vol. 86, no. 7, pp. 2336-2340, 1989.

[25] A. Durudas, J. M. Milush, H.-L. Chen, J. C. Engram, G. Silvestri, and D. L. Sodora, "Elevated levels of innate immune modulators in lymph nodes and blood are associated with more-rapid disease progression in simian immunodeficiency virus-infected monkeys," Journal of Virology, vol. 83, no. 23, pp. 12229-12240, 2009.

[26] S. L. Macura, M. J. Lathrop, J. Gui, G. F. Doncel, S. N. Asin, and C. Rollenhagen, "Blocking cxcl9 decreases HIV-1 replication and enhances the activity of prophylactic antiretrovirals in human cervical tissues," JAIDS Journal of Acquired Immune Deficiency Syndromes, vol. 71, no. 5, pp. 474-482, 2016.

[27] P. P. Gumbi, N. N. Nkwanyana, A. Bere et al., "Impact of mucosal inflammation on cervical human immunodeficiency virus (HIV-1)-specific CD8 T-cell responses in the female genital tract during chronic HIV infection," Journal of Virology, vol. 82, no. 17, pp. 8529-8536, 2008.

[28] G. R. Campbell and S. A. Spector, "CCL2 increases X4-tropic HIV-1 entry into resting CD4+ T cells," Journal of Biological Chemistry, vol. 283, no. 45, pp. 30745-30753, 2008.

[29] R. Kaul, A. Rebbapragada, T. Hirbod et al., "Genital levels of soluble immune factors with anti-HIV activity may correlate with increased HIV susceptibility," AIDS, vol. 22, no. 15, pp. 2049-2051, 2008.

[30] N. N. Nkwanyana, P. P. Gumbi, L. Roberts et al., "Impact of human immunodeficiency virus 1 infection and inflammation on the composition and yield of cervical mononuclear cells in the female genital tract," Immunology, vol. 128, no. 1pt2, pp. e746-e757, 2009.

[31] K. B. Arnold, A. Burgener, K. Birse et al., "Increased levels of inflammatory cytokines in the female reproductive tract are associated with altered expression of proteases, mucosal barrier proteins, and an influx of HIV-susceptible target cells," Mucosal Immunology, vol. 9, no. 1, pp. 194-205, 2016.

[32] E. M. Kahle, M. Bolton, J. P. Hughes et al., "Plasma cytokine levels and risk of HIV type 1 (HIV-1) transmission and acquisition: a nested case-control study among HIV-1serodiscordant couples," The Journal of Infectious Diseases, vol. 211, no. 9, pp. 1451-1460, 2015.

[33] V. Naranbhai, S. S. Abdool Karim, M. Altfeld et al., "Innate immune activation enhances HIV acquisition in women, diminishing the effectiveness of tenofovir microbicide gel," The Journal of Infectious Diseases, vol. 206, no. 7, pp. 9931001, 2012. 
[34] P. Levinson, R. Kaul, J. Kimani et al., "Levels of innate immune factors in genital fluids: association of alpha defensins and LL-37 with genital infections and increased HIV acquisition," AIDS, vol. 23, no. 3, pp. 309-317, 2009.

[35] A. Nazli, O. Chan, W. N. Dobson-Belaire et al., "Exposure to HIV-1 directly impairs mucosal epithelial barrier integrity allowing microbial translocation," PLoS Pathogens, vol. 6, no. 4, Article ID e1000852, 2010.

[36] A. H. Gitter, K. Bendfeldt, H. Schmitz, J. D. Schulzke, C. J. Bentzel, and M. Fromm, "Epithelial barrier defects in HT-29/b6 colonic cell monolayers induced by tumor necrosis factor-alpha," Annals of the New York Academy of Sciences, vol. 915, pp. 193-203, 2000.

[37] I. Grotjohann, H. Schmitz, M. Fromm, and J. D. Schulzke, "Effect of TNF alpha and IFN gamma on epithelial barrier function in rat rectum in vitro," Annals of the New York Academy of Sciences, vol. 915, pp. 282-286, 2000.

[38] J. Mankertz, S. Tavalali, H. Schmitz et al., "Expression from the human occludin promoter is affected by tumor necrosis factor alpha and interferon gamma," Journal of Cell Science, vol. 113, pp. 2085-2090, 2000.

[39] H. Schmitz, M. Fromm, C. J. Bentzel et al., "Tumor necrosis factor-alpha (TNF alpha) regulates the epithelial barrier in the human intestinal cell line HT-29/b6," Journal of Cell Science, vol. 112, no. 1, pp. 137-146, 1999.

[40] J. L. Madara and J. Stafford, "Interferon-gamma directly affects barrier function of cultured intestinal epithelial monolayers," Journal of Clinical Investigation, vol. 83, no. 2, pp. 724-727, 1989.

[41] A. Burgener, I. Mcgowan, and N. R. Klatt, "HIV and mucosal barrier interactions: consequences for transmission and pathogenesis," Current Opinion in Immunology, vol. 36, pp. 22-30, 2015.

[42] J. M. Reynolds, G. J. Martinez, K. C. Nallaparaju, S. H. Chang, Y.-H. Wang, and C. Dong, "Cutting edge: regulation of intestinal inflammation and barrier function by IL-17C," The Journal of Immunology, vol. 189, no. 9, pp. 4226-4230, 2012.

[43] Q. Li, J. D. Estes, P. M. Schlievert et al., "Glycerol monolaurate prevents mucosal SIV transmission," Nature, vol. 458, no. 7241, pp. 1034-1038, 2009.

[44] M. Alfano and G. Poli, "Role of cytokines and chemokines in the regulation of innate immunity and HIV infection," Molecular Immunology, vol. 42, no. 2, pp. 161-182, 2005.

[45] D. Masopust and J. M. Schenkel, "The integration of T cell migration, differentiation and function," Nature Reviews Immunology, vol. 13, no. 5, pp. 309-320, 2013.

[46] M. M. Stanford and T. B. Issekutz, "The relative activity of CXCR3 and CCR5 ligands in T lymphocyte migration: concordant and disparate activities in vitro and in vivo," Journal of Leukocyte Biology, vol. 74, no. 5, pp. 791-799, 2003.

[47] C. R. Wira, J. V. Fahey, C. L. Sentman, P. A. Pioli, and L. Shen, "Innate and adaptive immunity in female genital tract: cellular responses and interactions," Immunological Reviews, vol. 206, no. 1, pp. 306-335, 2005.

[48] M.-C. Dieu-Nosjean, A. Vicari, S. Lebecque, and C. Caux, "Regulation of dendritic cell trafficking: a process that involves the participation of selective chemokines," Journal of Leukocyte Biology, vol. 66, no. 2, pp. 252-262, 1999.

[49] A. Mueller and P. G. Strange, "The chemokine receptor, CCR5," The International Journal of Biochemistry \& Cell Biology, vol. 36, no. 1, pp. 35-38, 2004.

[50] A. Mueller and P. G. Strange, "CCL3, acting via the chemokine receptor CCR5, leads to independent activation of janus kinase 2 (JAK2) and giproteins," FEBS Letters, vol. 570, no. 1-3, pp. 126-132, 2004.

[51] J. S. Rawlings, K. M. Rosler, and D. A. Harrison, "The JAK/ STAT signaling pathway," Journal of Cell Science, vol. 117, no. 8, pp. 1281-1283, 2004.

[52] M. H. Kaplan, "STAT signaling in inflammation," JAKSTAT, vol. 2, Article ID e24198, 2013.

[53] P. Piot and M. Laga, "Genital ulcers, other sexually transmitted diseases, and the sexual transmission of HIV," Bmj, vol. 298, no. 6674, pp. 623-624, 1989.

[54] S. R. Galvin and M. S. Cohen, "The role of sexually transmitted diseases in HIV transmission," Nature Reviews Microbiology, vol. 2, no. 1, pp. 33-42, 2004.

[55] H. Ward and M. Rönn, "Contribution of sexually transmitted infections to the sexual transmission of HIV," Current Opinion in HIV and AIDS, vol. 5, no. 4, pp. 305-310, 2010.

[56] L. Masson, K. Mlisana, F. Little et al., "Defining genital tract cytokine signatures of sexually transmitted infections and bacterial vaginosis in women at high risk of HIV infection: a cross-sectional study," Sexually Transmitted Infections, vol. 90, no. 8, pp. 580-587, 2014.

[57] L. Masson, A. L. Salkinder, A. J. Olivier et al., "Relationship between female genital tract infections, mucosal interleukin17 production and local Thelper type 17 cells," Immunology, vol. 146, no. 4, pp. 557-567, 2015.

[58] R. Mwatelah, L. R. Mckinnon, C. Baxter, Q. Abdool Karim, and S. S. Abdool Karim, "Mechanisms of sexually transmitted infection-induced inflammation in women: implications for HIV risk," Journal of the International AIDS Society, vol. 22, no. suppl 6, Article ID e25346, 2019.

[59] K. Mlisana, N. Naicker, L. Werner et al., "Symptomatic vaginal discharge is a poor predictor of sexually transmitted infections and genital tract inflammation in high-risk women in South Africa," The Journal of Infectious Diseases, vol. 206, no. 1, pp. 6-14, 2012.

[60] B. Shannon, T. J. Yi, J. Thomas-Pavanel et al., "Impact of asymptomatic herpes simplex virus type 2 infection on mucosal homing and immune cell subsets in the blood and female genital tract," The Journal of Immunology, vol. 192, no. 11, pp. 5074-5082, 2014.

[61] V. Marsden, H. Donaghy, K. M. Bertram et al., "Herpes simplex virus type 2 -infected dendritic cells produce TNF- $\alpha$, which enhances CCR5 expression and stimulates HIV production from adjacent infected cells," The Journal of Immunology, vol. 194, no. 9, pp. 4438-4445, 2015.

[62] C. F. Houlihan, N. L. Larke, D. Watson-Jones et al., "Human papillomavirus infection and increased risk of HIV acquisition. A systematic review and meta-analysis," AIDS, vol. 26, no. 17, pp. 2211-2222, 2012.

[63] B. Auvert, D. Marais, P. Lissouba, K. Zarca, G. Ramjee, and A. L. Williamson, "High-risk human papillomavirus is associated with HIV acquisition among south african female sex workers," Infectious Diseases in Obstetrics and Gynecology, vol. 2011, Article ID 692012, 9 pages, 2011.

[64] G. A. Jarvis and T. L. Chang, "Modulation of HIV transmission by Neisseria gonorrhoeae: molecular and immunological aspects," Current HIV Research, vol. 10, no. 3, pp. 211-217, 2012.

[65] L. R. Buckner, A. M. Amedee, H. L. Albritton et al., "Chlamydia trachomatis infection of endocervical epithelial cells enhances early HIV transmission events," PLoS One, vol. 11, Article ID e0146663, 2016. 
[66] S. N. Mavedzenge, B. V. Pol, H. Cheng et al., "Epidemiological synergy of Trichomonas vaginalis and HIV in Zimbabwean and South African women," Sexually Transmitted Diseases, vol. 37, no. 7, pp. 460-466, 2010.

[67] E. B. Quinlivan, S. N. Patel, C. A. Grodensky, C. E. Golin, H.-C. Tien, and M. M. Hobbs, "Modeling the impact of Trichomonas vaginalis infection on HIV transmission in HIV-infected individuals in medical care," Sexually Transmitted Diseases, vol. 39, no. 9, pp. 671-677, 2012.

[68] A. B. Onderdonk, M. L. Delaney, and R. N. Fichorova, "The human microbiome during bacterial vaginosis," Clinical Microbiology Reviews, vol. 29, no. 2, pp. 223-238, 2016.

[69] A. R. Thurman, T. Kimble, B. Herold et al., "Bacterial vaginosis and subclinical markers of genital tract inflammation and mucosal immunity," AIDS Research and Human Retroviruses, vol. 31, no. 11, pp. 1139-1152, 2015.

[70] M. N. Anahtar, E. H. Byrne, K. E. Doherty et al., "Cervicovaginal bacteria are a major modulator of host inflammatory responses in the female genital tract," Immunity, vol. 42, no. 5, pp. 965-976, 2015.

[71] K. Lennard, S. Dabee, S. L. Barnabas et al., "Microbial composition predicts genital tract inflammation and persistent bacterial vaginosis in south African adolescent females," Infection and Immunity, vol. 86, no. 1, 2018.

[72] J. Atashili, C. Poole, P. M. Ndumbe, a. A. Adimora, and J. S. Smith, "Bacterial vaginosis and HIV acquisition: a metaanalysis of published studies," AIDS, vol. 22, no. 12, pp. 1493-1501, 2008.

[73] D. J. Alcendor, "Evaluation of health disparity in bacterial vaginosis and the implications for HIV-1 acquisition in African American women," American Journal of Reproductive Immunology, vol. 76, no. 2, pp. 99-107, 2016.

[74] T. E. Taha, D. R. Hoover, G. A. Dallabetta et al., "Bacterial vaginosis and disturbances of vaginal flora: association with increased acquisition of HIV," AIDS, vol. 12, no. 13, pp. 1699-1706, 1998.

[75] C. Gosmann, M. N. Anahtar, S. A. Handley et al., "Lactobacillus-deficient cervicovaginal bacterial communities are associated with increased HIV acquisition in young south african women," Immunity, vol. 46, no. 1, pp. 29-37, 2017.

[76] R. S. Mcclelland, J. R. Lingappa, S. Srinivasan et al., "Evaluation of the association between the concentrations of key vaginal bacteria and the increased risk of HIV acquisition in African women from five cohorts: a nested case-control study," The Lancet Infectious Diseases, vol. 18, no. 5, pp. 554-564, 2018.

[77] L. J. P. Liebenberg, D. Archary, A. Sivro, and D. S. Kwon, "Bugs, drugs, and HIV: the role of the vaginal microbiome in HIV risk and antiretroviral efficacy for HIV prevention," Genome Medicine, vol. 9, p. 74, 2017.

[78] Y. Chen, E. Bruning, J. Rubino, and S. E. Eder, "Role of female intimate hygiene in vulvovaginal health: global hygiene practices and product usage," Women's Health, vol. 13, no. 3, pp. 58-67, 2017.

[79] J. E. Brown and R. C. Brown, "Traditional intravaginal practices and the heterosexual transmission of disease: a review," Sexually Transmitted Diseases, vol. 27, no. 4, pp. 183-187, 2000.

[80] A. M. Hilber, M. F. Chersich, J. H. H. M. Van de Wijgert, H. Rees, and M. Temmerman, "Vaginal practices, microbicides and HIV: what do we need to know?", Sexually Transmitted Infections, vol. 83, no. 7, pp. 505-508, 2007.

[81] N. Low, M. F. Chersich, K. Schmidlin et al., "Intravaginal practices, bacterial vaginosis, and HIV infection in women: individual participant data meta-analysis," PLoS Medicine, vol. 8, Article ID e1000416, 2011.

[82] B. Fashemi, M. L. Delaney, A. B. Onderdonk, and R. N. Fichorova, "Effects of feminine hygiene products on the vaginal mucosal biome," Microbial Ecology in Health and Disease, vol. 24, 2013.

[83] E. Aslan and N. Bechelaghem, "To "douche" or not to "douche": hygiene habits may have detrimental effects on vaginal microbiota," Journal of Obstetrics and Gynaecology, vol. 38, no. 5, pp. 678-681, 2018.

[84] R. M. Brotman, M. A. Klebanoff, T. R. Nansel et al., "A longitudinal study of vaginal douching and bacterial vaginosis-a marginal structural modeling analysis," American Journal of Epidemiology, vol. 168, no. 2, pp. 188-196, 2008.

[85] R. M. Brotman, K. G. Ghanem, M. A. Klebanoff, T. E. Taha, D. O. Scharfstein, and J. M. Zenilman, "The effect of vaginal douching cessation on bacterial vaginosis: a pilot study," American Journal of Obstetrics and Gynecology, vol. 198, p. $628,2008$.

[86] M. C. Sabo, D. A. Lehman, B. Wang et al., "Associations between vaginal bacteria implicated in HIV acquisition risk and proinflammatory cytokines and chemokines," Sexually Transmitted Infections, vol. 96, no. 1, pp. 3-9, 2020.

[87] J. Poudrier, V. Thibodeau, and M. Roger, "Natural immunity to HIV: a delicate balance between strength and control," Clinical and Developmental Immunology, vol. 2012, Article ID 875821, 10 pages, 2012.

[88] R. Shen and P. D. Smith, "Mucosal correlates of protection in HIV-1-exposed sero-negative persons," American Journal of Reproductive Immunology, vol. 72, no. 2, pp. 219-227, 2014.

[89] J. Lajoie, J. Juno, A. Burgener et al., "A distinct cytokine and chemokine profile at the genital mucosa is associated with HIV-1 protection among HIV-exposed seronegative commercial sex workers," Mucosal Immunology, vol. 5, no. 3, pp. 277-287, 2012.

[90] S. Boulet, M. Kleyman, J. Y. Kim et al., “A combined genotype of kir3dll high expressing alleles and HLA-b $* 57$ is associated with a reduced risk of HIV infection," AIDS, vol. 22, no. 12, pp. 1487-1491, 2008.

[91] W. Jennes, S. Verheyden, C. Demanet et al., "Cutting edge: resistance to HIV-1 infection among African female sex workers is associated with inhibitory KIR in the absence of their HLA ligands," The Journal of Immunology, vol. 177, no. 10, pp. 6588-6592, 2006.

[92] K. S. Macdonald, K. R. Fowke, J. Kimani et al., "Influence of HLA supertypes on susceptibility and resistance to human immunodeficiency virus type 1 infection," The Journal of Infectious Diseases, vol. 181, no. 5, pp. 1581-1589, 2000.

[93] T. B. Ball, h. Ji, j. Kimani et al., "Polymorphisms in IRF-1 associated with resistance to HIV-1 infection in highly exposed uninfected Kenyan sex workers," AIDS, vol. 21, no. 9, pp. 1091-1101, 2007.

[94] M. W. Smith, M. Dean, M. Carrington et al., "Contrasting genetic influence of CCR2 and CCR5 variants on HIV-1 infection and disease progression. Hemophilia growth and development study (HGDS), multicenter aids cohort study (MACS), multicenter hemophilia cohort study (MHCS), san francisco city cohort (SFCC), alive study," Science, vol. 277, no. 5328, pp. 959-965, 1997.

[95] E. Gonzalez, H. Kulkarni, H. Bolivar et al., "The influence of CCL311 gene-containing segmental duplications on HIV-1/ AIDS susceptibility," Science, vol. 307, no. 5714, pp. 1434-1440, 2005. 
[96] T. Kawamura, F. O. Gulden, M. Sugaya et al., "R5 HIV productively infects Langerhans cells, and infection levels are regulated by compound CCR5 polymorphisms," Proceedings of the National Academy of Sciences, vol. 100, no. 14, pp. 8401-8406, 2003.

[97] P. A. Zimmerman, A. Buckler-White, G. Alkhatib et al., "Inherited resistance to HIV-1 conferred by an inactivating mutation in cc chemokine receptor 5: studies in populations with contrasting clinical phenotypes, defined racial background, and quantified risk," Molecular Medicine, vol. 3, no. 1, pp. 23-36, 1997.

[98] M. Dean, M. Carrington, C. Winkler et al., "Genetic restriction of HIV-1 infection and progression to aids by a deletion allele of the ckr5 structural gene. Hemophilia growth and development study, multicenter aids cohort study, multicenter hemophilia cohort study, San Francisco city cohort, alive study," Science, vol. 273, no. 5283, pp. 1856-1862, 1996.

[99] M. Biasin, S. L. Caputo, L. Speciale et al., "Mucosal and systemic immune activation is present in human immunodeficiency virus-exposed seronegative women," The Journal of Infectious Diseases, vol. 182, no. 5, pp. 1365-1374, 2000.

[100] C. Tomescu, S. Abdulhaqq, and L. J. Montaner, "Evidence for the innate immune response as a correlate of protection in human immunodeficiency virus (HIV)-1 highly exposed seronegative subjects (HESN)," Clinical \& Experimental Immunology, vol. 164, no. 2, pp. 158-169, 2011.

[101] M. H. Malim and P. D. Bieniasz, "HIV restriction factors and mechanisms of evasion," Cold Spring Harbor Perspectives in Medicine, vol. 2, Article ID a006940, 2012.

[102] K. Mous, W. Jennes, M. Camara et al., "Expression analysis of LEDGF/p75, APOBEC3G, TRIM5ALPHA, and tetherin in a senegalese cohort of HIV-1-exposed seronegative individuals," PLoS One, vol. 7, no. 3, Article ID e33934, 2012.

[103] S. M. Iqbal, T. B. Ball, P. Levinson et al., "Elevated elafin/ trappin-2 in the female genital tract is associated with protection against HIV acquisition," AIDS, vol. 23, no. 13, pp. 1669-1677, 2009.

[104] X.-D. Yao, R. W. Omange, B. M. Henrick et al., “Acting locally: innate mucosal immunity in resistance to HIV-1 infection in Kenyan commercial sex workers," Mucosal Immunology, vol. 7, no. 2, pp. 268-279, 2014.

[105] R. G. Gaudet, F. Breden, F. Plummer, and J. D. Berry, "Molecular characterization of the cervical and systemic B-cell repertoire: unique, yet overlapping, immune compartments of an HIV-1 resistant individual," MABS, vol. 3, no. 2, pp. 181-191, 2011.

[106] S. A. Stranford, J. Skurnick, D. Louria et al., "Lack of infection in HIV-exposed individuals is associated with a strong CD8+ cell noncytotoxic anti-HIV response," Proceedings of the National Academy of Sciences, vol. 96, no. 3, pp. 1030-1035, 1999.

[107] K. R. Fowke, R. Kaul, K. L. Rosenthal et al., "HIV-1-specific cellular immune responses among HIV-1-resistant sex workers," Immunology and Cell Biology, vol. 78, no. 6, pp. 586-595, 2000.

[108] J. B. Alimonti, S. A. Koesters, J. Kimani et al., "CD4+ T cell responses in HIV-exposed seronegative women are qualitatively distinct from those in HIV-infected women," The Journal of Infectious Diseases, vol. 191, no. 1, pp. 20-24, 2005.

[109] S. M. Iqbal, T. B. Ball, J. Kimani et al., "Elevated T cell counts and RANTES expression in the genital mucosa of HIV-1- resistant Kenyan commercial sex workers," The Journal of Infectious Diseases, vol. 192, no. 5, pp. 728-738, 2005.

[110] R. Kaul, D. Trabattoni, J. J. Bwayo et al., "HIV-1-specific mucosal IGA in a cohort of HIV-1-resistant Kenyan sex workers," AIDS, vol. 13, no. 1, pp. 23-29, 1999.

[111] C. Devito, J. Hinkula, R. Kaul et al., "Cross-clade HIV-1specific neutralizing iga in mucosal and systemic compartments of HIV-1-exposed, persistently seronegative subjects," JAIDS Journal of Acquired Immune Deficiency Syndromes, vol. 30, no. 4, pp. 413-420, 2002.

[112] L. Bélec, P. D. Ghys, H. Hocini et al., "Cervicovaginal secretory antibodies to human immunodeficiency virus type 1 (HIV-1) that block viral transcytosis through tight epithelial barriers in highly exposed HIV-1-seronegative African women," The Journal of Infectious Diseases, vol. 184, no. 11, pp. 1412-1422, 2001.

[113] R. Kaul, F. A. Plummer, J. Kimani et al., "HIV-1-specific mucosal CD8+ lymphocyte responses in the cervix of HIV-1resistant prostitutes in Nairobi," The Journal of Immunology, vol. 164, no. 3, pp. 1602-1611, 2000.

[114] S. L. Rowland-Jones, T. Dong, K. R. Fowke et al., "Cytotoxic T cell responses to multiple conserved HIV epitopes in HIVresistant prostitutes in Nairobi," Journal of Clinical Investigation, vol. 102, no. 9, pp. 1758-1765, 1998.

[115] J. R. Almeida, D. A. Price, L. Papagno et al., "Superior control of HIV-1 replication by CD8+ T cells is reflected by their avidity, polyfunctionality, and clonal turnover," Journal of Experimental Medicine, vol. 204, no. 10, pp. 2473-2485, 2007.

[116] I. Saulle, S. V. Ibba, C. Vittori et al., "Sterol metabolism modulates susceptibility to HIV-1 infection," AIDS, vol. 34, no. 11, pp. 1593-1602, 2020.

[117] M. Biasin, L. Piacentini, S. Lo Caputo et al., "TLR activation pathways in HIV-1-exposed seronegative individuals," The Journal of Immunology, vol. 184, no. 5, pp. 2710-2717, 2010.

[118] V. Ramakrishna, J. P. Vasilakos, J. D. Tario Jr., M. A. Berger, P. K. Wallace, and T. Keler, "Toll-like receptor activation enhances cell-mediated immunity induced by an antibody vaccine targeting human dendritic cells," Journal of Translational Medicine, vol. 5, p. 5, 2007.

[119] C. Maisonneuve, S. Bertholet, D. J. Philpott, and E. De Gregorio, "Unleashing the potential of NOD- and tolllike agonists as vaccine adjuvants," Proceedings of the $\mathrm{Na}$ tional Academy of Sciences, vol. 111, no. 34, pp. 12294-12299, 2014.

[120] K. R. Fowke, N. J. Nagelkerke, J. Kimani et al., "Resistance to HIV-1 infection among persistently seronegative prostitutes in Nairobi, Kenya," The Lancet, vol. 348, no. 9038, pp. 1347-1351, 1996.

[121] I. Pandrea, D. L. Sodora, G. Silvestri, and C. Apetrei, "Into the wild: Simian immunodeficiency virus (SIV) infection in natural hosts," Trends in Immunology, vol. 29, no. 9, pp. 419-428, 2008.

[122] M. Paiardini, B. Cervasi, E. Reyes-Aviles et al., "Low levels of SIV infection in sooty mangabey central memory CD4+ T cells are associated with limited CCR5 expression," Nature Medicine, vol. 17, no. 7, pp. 830-836, 2011.

[123] J. N. Mandl, A. P. Barry, T. H. Vanderford et al., "Divergent TLR7 and TLR9 signaling and type I interferon production distinguish pathogenic and nonpathogenic AIDS virus infections," Nature Medicine, vol. 14, no. 10, pp. 1077-1087, 2008.

[124] J. M. Brenchley, M. Paiardini, K. S. Knox et al., "Differential TH17 CD4 T-cell depletion in pathogenic and 
nonpathogenic lentiviral infections," Blood, vol. 112, no. 7, pp. 2826-2835, 2008.

[125] D. Chege, Y. Chai, S. Huibner et al., "Blunted IL17/IL22 and pro-inflammatory cytokine responses in the genital tract and blood of HIV-exposed, seronegative female sex workers in Kenya," PLoS One, vol. 7, no. 8, Article ID e43670, 2012.

[126] C. M. Card, Y. Keynan, J. Lajoie et al., "HIV controllers are distinguished by chemokine expression profile and HIVspecific T-cell proliferative potential," JAIDS Journal of Acquired Immune Deficiency Syndromes, vol. 59, no. 5, pp. 427-437, 2012.

[127] P. J. Mclaren, T. B. Ball, C. Wachihi et al., "HIV-exposed seronegative commercial sex workers show a quiescent phenotype in the CD4+ T cell compartment and reduced expression of HIV-dependent host factors," The Journal of Infectious Diseases, vol. 202, no. S3, pp. s339-S344, 2010.

[128] J. L. Prodger, T. Hirbod, G. Kigozi et al., "Immune correlates of HIV exposure without infection in foreskins of men from Rakai, Uganda," Mucosal Immunology, vol. 7, no. 3, pp. 634-644, 2014.

[129] C. M. Card, P. J. Mclaren, C. Wachihi, J. Kimani, F. A. Plummer, and K. R. Fowke, "Decreased immune activation in resistance to HIV-1 infection is associated with an elevated frequency of CD4+ CD25+ FOXP3+ regulatory T cells," The Journal of Infectious Diseases, vol. 199, no. 9, pp. 1318-1322, 2009.

[130] C. M. Card, W. J. Rutherford, S. Ramdahin et al., "Reduced cellular susceptibility to in vitro HIV infection is associated with CD4+ T cell quiescence," PLoS One, vol. 7, no. 9, Article ID e45911, 2012.

[131] F. A. Koning, S. A. Otto, M. D. Hazenberg et al., "Low-level CD4+ T cell activation is associated with low susceptibility to HIV-1 infection," The Journal of Immunology, vol. 175, no. 9, pp. 6117-6122, 2005.

[132] E. Bégaud, L. Chartier, V. Marechal et al., "Reduced CD4 T cell activation and in vitro susceptibility to HIV-1 infection in exposed uninfected central Africans," Retrovirology, vol. 3, no. 1 , p. 35, 2006.

[133] M. Camara, T. N. Dieye, M. Seydi et al., "Low-level CD4+ $\mathrm{T}$ cell activation in HIV-exposed seronegative subjects: influence of gender and condom use," The Journal of Infectious Diseases, vol. 201, no. 6, pp. 835-842, 2010.

[134] R. Cromarty, A. Sigal, L. J. P. Liebenberg et al., "Diminished HIV infection of target CD4+ T cells in a toll-like receptor 4 stimulated in vitro model," Frontiers in Immunology, vol. 10, p. 1705, 2019.

[135] E. M. Songok, M. Luo, B. Liang et al., "Microarray analysis of HIV resistant female sex workers reveal a gene expression signature pattern reminiscent of a lowered immune activation state," PLoS One, vol. 7, no. 1, Article ID e30048, 2012.

[136] S. Brand, F. Beigel, T. Olszak et al., "IL-22 is increased in active Crohn's disease and promotes proinflammatory gene expression and intestinal epithelial cell migration," American Journal of Physiology-Gastrointestinal and Liver Physiology, vol. 290, no. 4, pp. g827-G838, 2006.

[137] H. Xu, X. Wang, and R. S. Veazey, "TH17 cells coordinate with $\mathrm{TH} 22$ cells in maintaining homeostasis of intestinal tissues and both are depleted in SIV-infected macaques," Journal of AIDS \& Clinical Research, vol. 5, 2014.

[138] K. Sugimoto, A. Ogawa, E. Mizoguchi et al., "IL-22 ameliorates intestinal inflammation in a mouse model of ulcerative colitis," Journal of Clinical Investigation, vol. 118, pp. 534-544, 2008.
[139] N. R. Klatt and J. M. Brenchley, "TH17 cell dynamics in HIV infection," Current Opinion in HIV and AIDS, vol. 5, no. 2, pp. 135-140, 2010.

[140] M. Rodriguez-Garcia, F. D. Barr, S. G. Crist, J. V. Fahey, and C. R. Wira, "Phenotype and susceptibility to HIV infection of CD4+ TH17 cells in the human female reproductive tract," Mucosal Immunology, vol. 7, no. 6, pp. 1375-1385, 2014.

[141] D. J. Stieh, E. Matias, H. Xu et al., “TH17 cells are preferentially infected very early after vaginal transmission of SIV in macaques," Cell Host \& Microbe, vol. 19, no. 4, pp. 529-540, 2016.

[142] L. R. Mckinnon, B. Nyanga, D. Chege et al., "Characterization of a human cervical CD4+ T cell subset coexpressing multiple markers of HIV susceptibility," The Journal of Immunology, vol. 187, no. 11, pp. 6032-6042, 2011.

[143] L. R. Mckinnon, B. Nyanga, C. J. Kim et al., "Early HIV-1 infection is associated with reduced frequencies of cervical TH17 cells," JAIDS Journal of Acquired Immune Deficiency Syndromes, vol. 68, no. 1, pp. 6-12, 2015.

[144] S. Zicari, L. Sessa, N. Cotugno et al., "Immune activation, inflammation, and non-aids co-morbidities in HIV-infected patients under long-term art," Viruses, vol. 11, 2019.

[145] J. Slim and C. F. Saling, "A review of management of inflammation in the HIV population," Biomed Research International, vol. 2016, Article ID 3420638, 12 pages, 2016.

[146] P. E. Tarr and A. Calmy, "Anti-inflammatory therapy in well controlled HIV infection," The Lancet HIV, vol. 5, no. 10, pp. e538-e539, 2018.

[147] S. M. Murray, C. M. Down, D. R. Boulware et al., "Reduction of immune activation with chloroquine therapy during chronic HIV infection," Journal of Virology, vol. 84, no. 22, pp. 12082-12086, 2010.

[148] J. M. Jacobson, S. E. Bosinger, M. Kang et al., "The effect of chloroquine on immune activation and interferon signatures associated with HIV-1," AIDS Research and Human Retroviruses, vol. 32, no. 7, pp. 636-647, 2016.

[149] S. Lederman, S. Parisotto, G. Rizzardini et al., "Hydroxychloroquine drastically reduces immune activation in $\mathrm{HIV}$-infected, antiretroviral therapy-treated immunologic nonresponders," Blood, vol. 118, no. 12, pp. 3263-3272, 2011.

[150] N. I. Paton, R. L. Goodall, D. T. Dunn et al., "Effects of hydroxychloroquine on immune activation and disease progression among $\mathrm{HIV}$-infected patients not receiving antiretroviral therapy: a randomized controlled trial," JAMA, vol. 308, pp. 353-361, 2012.

[151] E. N. Kersh, W. Luo, Q. Zheng et al., "Reduced inflammation and CD4 loss in acute SHIV infection during oral pre-exposure prophylaxis," Journal of Infectious Diseases, vol. 206, no. 5, pp. 770-779, 2012.

[152] J. R. Castillo-Mancilla, A. Meditz, C. Wilson et al., "Reduced immune activation during tenofovir-emtricitabine therapy in HIV-negative individuals," JAIDS Journal of Acquired Immune Deficiency Syndromes, vol. 68, no. 5, pp. 495-501, 2015.

[153] L. Pattacini, P. M. Murnane, J. M. Baeten et al., "Antiretroviral pre-exposure prophylaxis does not enhance immune responses to HIV in exposed but uninfected persons," Journal of Infectious Diseases, vol. 211, no. 12, pp. 1943-1952, 2015.

[154] A. Abdulla, N. Adams, M. Bone et al., "Guidance on the management of pain in older people," Age Ageing, vol. 42, no. 1, pp. i1-57, 2013. 
[155] G. Onder, F. Pellicciotti, G. Gambassi, and R. Bernabei, "NSAID-related psychiatric adverse events: who is at risk?," Drugs, vol. 64, no. 23, pp. 2619-2627, 2004.

[156] R. N. Dubois, S. B. Abramson, L. Crofford et al., "Cyclooxygenase in biology and disease," The FASEB Journal, vol. 12, pp. 1063-1073, 1998.

[157] E. Ricciotti and G. A. Fitzgerald, "Prostaglandins and inflammation," Arteriosclerosis, Thrombosis, and Vascular Biology, vol. 31, no. 5, pp. 986-1000, 2011.

[158] D. P. Symmons, "Safety profile of low-dose aspirin," The Lancet, vol. 348, no. 9039, pp. 1394-1395, 1996.

[159] R. B. Lipton, J. Goldstein, J. S. Baggish, A. R. Yataco, J. V. Sorrentino, and J. N. Quiring, "Aspirin is efficacious for the treatment of acute migraine," Headache: The Journal of Head and Face Pain, vol. 45, no. 4, pp. 283-292, 2005.

[160] S. V. Ittaman, J. J. Vanwormer, and S. H. Rezkalla, "The role of aspirin in the prevention of cardiovascular disease," Clinical Medicine \& Research, vol. 12, no. 3-4, pp. 147-154, 2014.

[161] Y. Dai and J. Ge, "Clinical use of aspirin in treatment and prevention of cardiovascular disease," Thrombosis, vol. 2012, Article ID 245037, 7 pages, 2012.

[162] A. N. Mahmoud, M. M. Gad, A. Y. Elgendy, I. Y. Elgendy, and A. A. Bavry, "Efficacy and safety of aspirin for primary prevention of cardiovascular events: a meta-analysis and trial sequential analysis of randomized controlled trials," European Heart Journal, vol. 40, no. 7, pp. 607-617, 2019.

[163] R. D. Kehm, J. L. Hopper, E. M. John et al., "Regular use of aspirin and other non-steroidal anti-inflammatory drugs and breast cancer risk for women at familial or genetic risk: a cohort study," Breast Cancer Research, vol. 21, p. 52, 2019.

[164] A. T. Chan, E. L. Giovannucci, J. A. Meyerhardt, E. S. Schernhammer, G. C. Curhan, and C. S. Fuchs, "Longterm use of aspirin and nonsteroidal anti-inflammatory drugs and risk of colorectal cancer," JAMA, vol. 294, no. 8, pp. 914-923, 2005.

[165] J. Lajoie, K. Birse, L. Mwangi et al., "Using safe, affordable and accessible non-steroidal anti-inflammatory drugs to reduce the number of HIV target cells in the blood and at the female genital tract," Journal of the International AIDS Society, vol. 21, Article ID e25150, 2018.

[166] M. O’Brien, E. Montenont, L. Hu et al., "Aspirin attenuates platelet activation and immune activation in HIV-1-infected subjects on antiretroviral therapy: a pilot study," Journal of Acquired Immune Deficiency Syndromes, vol. 63, no. 3, pp. 280-288, 2013.

[167] F. Bradbury, "How important is the role of the physician in the correct use of a drug? An observational cohort study in general practice," International Journal of Clinical Practice, vol. 144, pp. 27-32, 2004.

[168] S. S. Adams, K. F. Mccullough, and J. S. Nicholson, "The pharmacological properties of ibuprofen, an anti-inflammatory, analgesic and antipyretic agent," Archives Internationales de Pharmacodynamie et de Therapie, vol. 178, no. 1, pp. 115-129, 1969.

[169] N. Moore, "Forty years of ibuprofen use," International Journal of Clinical Practice, vol. 135, pp. 28-31, 2003.

[170] S. C. Tan, B. K. Patel, S. H. Jackson, C. G. Swift, and A. J. Hutt, "Ibuprofen stereochemistry: double-the-trouble?," Enantiomer, vol. 4, pp. 195-203, 1999.

[171] M. I. Clemente, S. Alvarez, M. J. Serramía et al., "Nonsteroidal anti-inflammatory drugs increase the antiretroviral activity of nucleoside reverse transcriptase inhibitors in HIV type-1-infected T-lymphocytes: role of multidrug resistance protein 4," Antiviral Therapy, vol. 14, no. 8, pp. 1101-1111, 2009.

[172] A. S. Mulato, E. S. Ho, and T. Cihlar, "Nonsteroidal antiinflammatory drugs efficiently reduce the transport and cytotoxicity of adefovir mediated by the human renal organic anion transporter 1," The Journal of Pharmacology and Experimental Therapeutics, vol. 295, no. 1, pp. 10-15, 2000.

[173] M. Milani and P. Iacobelli, "Vaginal use of ibuprofen isobutanolammonium (ginenorm): efficacy, tolerability, and pharmacokinetic data: a review of available data," ISRN Obstetrics and Gynecology, vol. 2012, Article ID 673131, 6 pages, 2012.

[174] A. S. Bourinbaiar and S. Lee-Huang, "The non-steroidal antiinflammatory drug, indomethacin, as an inhibitor of HIV replication," FEBS Letters, vol. 360, no. 1, pp. 85-88, 1995.

[175] A. S. Bourinbaiar and S. Leehuang, "Potentiation of antiHIV activity of anti-inflammatory drugs, dexamethasone and indomethacin, by map30, the antiviral agent from bitter melon," Biochemical and Biophysical Research Communications, vol. 208, no. 2, pp. 779-785, 1995.

[176] M. A. Naarding, E. Baan, G. Pollakis, and W. A. Paxton, "Effect of chloroquine on reducing HIV-1 replication in vitro and the DC-sign mediated transfer of virus to CD4+ T-lymphocytes," Retrovirology, vol. 4, no. 1, p. 6, 2007.

[177] J. Stephenson, "Widely used spermicide may increase, not decrease, risk of HIV transmission," JAMA: The Journal of the American Medical Association, vol. 284, no. 8, p. 949, 2000.

[178] R. N. Fichorova, L. D. Tucker, and d. J. Anderson, "The molecular basis of nonoxynol-9-induced vaginal inflammation and its possible relevance to human immunodeficiency virus type 1 transmission," The Journal of Infectious Diseases, vol. 184, no. 4, pp. 418-428, 2001.

[179] K. Smith-Mccune, J. C. Chen, R. M. Greenblatt et al., "Unexpected inflammatory effects of intravaginal gels (universal placebo gel and nonoxynol-9) on the upper female reproductive tract: a randomized crossover study," PLoS One, vol. 10, no. 7, Article ID e0129769, 2015.

[180] Y. Chen, Y. L. Traore, S. Yang et al., "Implant delivering hydroxychloroquine attenuates vaginal $\mathrm{T}$ lymphocyte activation and inflammation," Journal of Controlled Release, vol. 277, pp. 102-113, 2018.

[181] M. D. Taves, C. E. Gomez-Sanchez, and K. K. Soma, "Extraadrenal glucocorticoids and mineralocorticoids: evidence for local synthesis, regulation, and function," American Journal of Physiology-Endocrinology and Metabolism, vol. 301, no. 1, pp. 11-24, 2011.

[182] S. Timmermans, J. Souffriau, and C. Libert, "A general introduction to glucocorticoid biology," Frontiers in Immunology, vol. 10, p. 1545, 2019.

[183] E. Ayroldi, L. Cannarile, G. Migliorati, G. Nocentini, D. V. Delfino, and C. Riccardi, "Mechanisms of the antiinflammatory effects of glucocorticoids: genomic and nongenomic interference with MAPK signaling pathways," The FASEB Journal, vol. 26, no. 12, pp. 4805-4820, 2012.

[184] D. W. Cain and J. A. Cidlowski, "Immune regulation by glucocorticoids," Nature Reviews Immunology, vol. 17, no. 4, pp. 233-247, 2017.

[185] C. Stahn and F. Buttgereit, "Genomic and nongenomic effects of glucocorticoids," Nature Clinical Practice Rheumatology, vol. 4, no. 10, pp. 525-533, 2008.

[186] S. Wüst, J. Van Den Brandt, D. Tischner et al., "Peripheral $\mathrm{T}$ cells are the therapeutic targets of glucocorticoids in 
experimental autoimmune encephalomyelitis," The Journal of Immunology, vol. 180, no. 12, pp. 8434-8443, 2008.

[187] A. A. Lackner, M. M. Lederman, and B. Rodriguez, "HIV pathogenesis: the host," Cold Spring Harbor Perspectives in Medicine, vol. 2, Article ID a007005, 2012.

[188] T. P. Lahey, S. D. Loisel, and W. Wieland-Alter, "Glucocorticoid-induced tumor necrosis factor receptor familyrelated protein triggering enhances HIV-specific CD4+ T cell cytokine secretion and protects HIV-specific CD4+ T cells from apoptosis," The Journal of Infectious Diseases, vol. 196, no. 1, pp. 43-49, 2007.

[189] S. K. Agarwal and G. D. Marshall Jr., "Dexamethasone promotes type 2 cytokine production primarily through inhibition of type 1 cytokines," Journal of Interferon \& Cytokine Research, vol. 21, no. 3, pp. 147-155, 2001.

[190] J. A. Kern, R. J. Lamb, J. C. Reed, R. P. Daniele, and P. C. Nowell, "Dexamethasone inhibition of interleukin 1 beta production by human monocytes. Post transcriptional mechanisms," Journal of Clinical Investigation, vol. 81, no. 1, pp. 237-244, 1988.

[191] A. Ristimaki, K. Narko, and T. Hla, "Down-regulation of cytokine-induced cyclo-oxygenase-2 transcript isoforms by dexamethasone: evidence for post-transcriptional regulation," Biochemical Journal, vol. 318, no. 1, pp. 325-331, 1996.

[192] X.-L. Yao, M. J. Cowan, M. T. Gladwin, M. M. Lawrence, C. W. Angus, and J. H. Shelhamer, "Dexamethasone alters arachidonate release from human epithelial cells by induction of $\mathrm{p} 11$ protein synthesis and inhibition of phospholipase A2 activity," Journal of Biological Chemistry, vol. 274, no. 24, pp. 17202-17208, 1999.

[193] R. Newton, J. Seybold, L. M. E. Kuitert, M. Bergmann, and P. J. Barnes, "Repression of cyclooxygenase- 2 and prostaglandin E2 release by dexamethasone occurs by transcriptional and post-transcriptional mechanisms involving loss of polyadenylated mRNA," Journal of Biological Chemistry, vol. 273, no. 48, pp. 32312-32321, 1998.

[194] T. Kino, J. B. Kopp, and G. P. Chrousos, "Glucocorticoids suppress human immunodeficiency virus type-1 long terminal repeat activity in a cell type-specific, glucocorticoid receptor-mediated fashion: direct protective effects at variance with clinical phenomenology," The Journal of Steroid Biochemistry and Molecular Biology, vol. 75, no. 4-5, pp. 283-290, 2000.

[195] T. W. Orlikowsky, Z. Q. Wang, A. Dudhane et al., "Dexamethasone inhibits CD4 $\mathrm{T}$ cell deletion mediated by macrophages from human immunodeficiency virus-infected persons," The Journal of Infectious Diseases, vol. 184, no. 10, pp. 1328-1330, 2001.

[196] M. Rosset, S. Steinberg, and R. K. Schachter, "Topical betamethasone: a double blind study," Applied Therapeutics, vol. 5, pp. 319-321, 1963.

[197] H. Mori, K. Arita, T. Yamaguchi, M. Hirai, and Y. Kurebayashi, "Effects of topical application of betamethasone on imiquimod-induced psoriasis-like skin inflammation in mice," Kobe Journal of Medical Sciences, vol. 62, pp. e79-e88, 2016.

[198] N. Powell, S. J. Till, A. B. Kay, and C. J. Corrigan, "The topical glucocorticoids beclomethasone dipropionate and fluticasone propionate inhibit human T-cell allergen-induced production of IL-5, IL-3 and GM-CSF mRNA and protein," Clinical \& Experimental Allergy, vol. 31, no. 1, pp. 69-76, 2001.

[199] R. Cromarty, A. Sigal, L. J. Liebenberg et al., "Betamethasone induces potent immunosuppression and reduces HIV infection in a PBMC in vitro model," Journal of Investigative Medicine, 2020.

[200] J. M. Andrieu and W. Lu, "Long-term clinical, immunologic and virologic impact of glucocorticoids on the chronic phase of HIV infection," BMC Medicine, vol. 2, p. 17, 2004.

[201] A. W. Ansari, R. E. Schmidt, and H. Heiken, "Prednisolone mediated suppression of HIV-1 viral load strongly correlates with c-c chemokine CCL2: in vivo and in vitro findings," Clinical Immunology, vol. 125, no. 1, pp. 1-4, 2007.

[202] C. Kasang, A. Ulmer, N. Donhauser et al., "HIV patients treated with low-dose prednisolone exhibit lower immune activation than untreated patients," BMC Infectious Diseases, vol. 12, p. 14, 2012.

[203] J.-M. Andrieu, W. Lu, and R. Levy, "Sustained increases in CD4 cell counts in asymptomatic human immunodeficiency virus type 1-seropositive patients treated with prednisolone for 1 year," Journal of Infectious Diseases, vol. 171, no. 3, pp. 523-530, 1995.

[204] W. Lu, R. Salerno-Goncalves, J. Yuan, D. Sylvie, D. S. Han, and J. M. Andrieu, "Glucocorticoids rescue CD4+ $\mathrm{T}$ lymphocytes from activation-induced apoptosis triggered by HIV-1: implications for pathogenesis and therapy," Aids, vol. 9, no. 1, pp. 35-42, 1995.

[205] A. Ulmer, M. Müller, B. Bertisch-Möllenhoff, and B. Frietsch, "Low-dose prednisolone has a CD4-stabilizing effect in pre-treated HIV-patients during structured therapy interruptions (STI)," European Journal of Medical Research, vol. 10, no. 6, pp. 227-232, 2005.

[206] C. Kasang, S. Kalluvya, C. Majinge et al., "Effects of prednisolone on disease progression in antiretroviral-untreated HIV infection: a 2-year randomized, double-blind placebocontrolled clinical trial," PLoS One, vol. 11, no. 1, Article ID e0146678, 2016.

[207] M. Fine, "Quantifying the impact of nsaid-associated adverse events," The American Journal of Managed Care, vol. 19, pp. s267-72, 2013.

[208] M. Oray, K. Abu Samra, N. Ebrahimiadib, H. Meese, and C. S. Foster, "Long-term side effects of glucocorticoids," Expert Opinion on Drug Safety, vol. 15, no. 4, pp. 457-465, 2016.

[209] J. L. Wallace, W. Mcknight, B. K. Reuter, and N. Vergnolle, "Nsaid-induced gastric damage in rats: requirement for inhibition of both cyclooxygenase 1 and 2," Gastroenterology, vol. 119 , no. 3 , pp. 706-714, 2000.

[210] r. Iwakiri, "NSAIDS and its gastrointestinal side effects: relation of nsaids variety and influence of concomitant medicine," Nihon Rinsho (Japanese Journal of Clinical Medicine), vol. 65, pp. 1776-1780, 2007.

[211] W. C. Winkelmayer, S. S. Waikar, H. Mogun, and D. H. Solomon, "Nonselective and cyclooxygenase-2-selective nsaids and acute kidney injury," The American Journal of Medicine, vol. 121, no. 12, pp. 1092-1098, 2008.

[212] S. Harirforoosh, W. Asghar, and F. Jamali, "Adverse effects of nonsteroidal antiinflammatory drugs: an update of gastrointestinal, cardiovascular and renal complications," Journal of Pharmacy \& Pharmaceutical Sciences, vol. 16, no. 5, pp. 821-847, 2013.

[213] P. C. Souverein, A. Berard, T. P. Van Staa et al., "Use of oral glucocorticoids and risk of cardiovascular and cerebrovascular disease in a population based case-control study," Heart, vol. 90, no. 8, pp. 859-865, 2004.

[214] L. Wei, T. M. Macdonald, and B. R. Walker, "Taking glucocorticoids by prescription is associated with subsequent 
cardiovascular disease," Annals of Internal Medicine, vol. 141, no. 10, pp. 764-770, 2004.

[215] A. Vegiopoulos and S. Herzig, "Glucocorticoids, metabolism and metabolic diseases," Molecular and Cellular Endocrinology, vol. 275, no. 1-2, pp. 43-61, 2007.

[216] W. Hu, Y. Zhang, W. Wu et al., "Chronic glucocorticoids exposure enhances neurodegeneration in the frontal cortex and hippocampus via NLRP-1 inflammasome activation in male mice," Brain, Behavior, and Immunity, vol. 52, pp. 58-70, 2016.

[217] S. Dhar, J. Seth, and D. Parikh, "Systemic side-effects of topical corticosteroids," Indian Journal of Dermatology, vol. 59, no. 5, pp. 460-464, 2014.

[218] R. Widrig, A. Suter, R. Saller, and J. Melzer, "Choosing between nsaid and arnica for topical treatment of hand osteoarthritis in a randomised, double-blind study," Rheumatology International, vol. 27, no. 6, pp. 585-591, 2007.

[219] U. E. Makris, M. J. Kohler, and L. Fraenkel, "Adverse effects of topical nonsteroidal anti-inflammatory drugs in older adults with osteoarthritis: a systematic literature review," The Journal of Rheumatology, vol. 37, no. 6, pp. 1236-1243, 2010.

[220] M. Farage and H. I. Maibach, "The vulvar epithelium differs from the skin: implications for cutaneous testing to address topical vulvar exposures," Contact Dermatitis, vol. 51, no. 4, pp. 201-209, 2004.

[221] H. Wang, W. Chen, D. Li et al., "Vitamin D and chronic diseases," Aging and Disease, vol. 8, no. 3, pp. 346-353, 2017.

[222] G. Carmeliet, V. Dermauw, and R. Bouillon, "Vitamin D signaling in calcium and bone homeostasis: a delicate balance," Best Practice \& Research Clinical Endocrinology \& Metabolism, vol. 29, no. 4, pp. 621-631, 2015.

[223] W. Dankers, E. M. Colin, J. P. Van Hamburg, and E. Lubberts, "Vitamin D in autoimmunity: molecular mechanisms and therapeutic potential," Frontiers in Immunology, vol. 7, p. 697, 2016.

[224] A. W. Norman, H. L. Henry, J. E. Bishop, X.-D. Song, c. Bula, and W. H. Okamura, "Different shapes of the steroid hormone $1 \alpha, 25(\mathrm{OH})_{2}$-vitamin D3 act as agonists for two different receptors in the vitamin $\mathrm{D}$ endocrine system to mediate genomic and rapid responses," Steroids, vol. 66, no. 3-5, pp. 147-158, 2001.

[225] J. M. Lemire and D. C. Archer, "1,25-dihydroxy vitamin D3 prevents the in vivo induction of murine experimental autoimmune encephalomyelitis," Journal of Clinical Investigation, vol. 87, no. 3, pp. 1103-1107, 1991.

[226] M. T. Cantorna, C. E. Hayes, and H. F. Deluca, "1,25dihydroxycholecalciferol inhibits the progression of arthritis in murine models of human arthritis," The Journal of $\mathrm{Nu}$ trition, vol. 128, no. 1, pp. 68-72, 1998.

[227] M. T. Cantorna, C. E. Hayes, and H. F. Deluca, "1,25dihydroxyvitamin D3 reversibly blocks the progression of relapsing encephalomyelitis, a model of multiple sclerosis," Proceedings of the National Academy of Sciences, vol. 93, no. 15, pp. 7861-7864, 1996.

[228] A. R. Mason, J. Mason, M. Cork, G. Dooley, and H. Hancock, "Topical treatments for chronic plaque psoriasis," Cochrane Database Systematic Review, 2013.

[229] T. Fujiyama, T. Ito, T. Umayahara et al., “Topical application of a vitamin D3 analogue and corticosteroid to psoriasis plaques decreases skin infiltration of TH17 cells and their ex vivo expansion," Journal of Allergy and Clinical Immunology, vol. 138, no. 2, pp. 517-528, 2016.

[230] S. Segaert, N. H. Shear, A. Chiricozzi et al., "Optimizing antiinflammatory and immunomodulatory effects of corticosteroid and vitamin D analogue fixed-dose combination therapy," Dermatology and Therapy, vol. 7, no. 3, pp. 265-279, 2017.

[231] S. D. Lawn, S. T. Butera, and T. M. Folks, "Contribution of immune activation to the pathogenesis and transmission of human immunodeficiency virus type 1 infection," Clinical Microbiology Reviews, vol. 14, no. 4, pp. 753-777, 2001.

[232] A. T. Haase, E. Rakasz, N. Schultz-Darken et al., "Glycerol monolaurate microbicide protection against repeat highdose SIV vaginal challenge," PLoS One, vol. 10, no. 6, Article ID e0129465, 2015.

[233] S. J. Projan, S. Brown-Skrobot, P. M. Schlievert, F. Vandenesch, and R. P. Novick, "Glycerol monolaurate inhibits the production of beta-lactamase, toxic shock toxin1 , and other staphylococcal exoproteins by interfering with signal transduction," Journal of Bacteriology, vol. 176, no. 14, pp. 4204-4209, 1994.

[234] P. M. Schlievert, J. R. Deringer, M. H. Kim, S. J. Projan, and R. P. Novick, "Effect of glycerol monolaurate on bacterial growth and toxin production," Antimicrobial Agents and Chemotherapy, vol. 36, no. 3, pp. 626-631, 1992.

[235] K. J. Witcher, R. P. Novick, and P. M. Schlievert, "Modulation of immune cell proliferation by glycerol monolaurate," Clinical and Diagnostic Laboratory Immunology, vol. 3, no. 1, pp. 10-13, 1996.

[236] M. L. Peterson and P. M. Schlievert, "Glycerol monolaurate inhibits the effects of gram-positive select agents on eukaryotic cells," Biochemistry, vol. 45, no. 7, pp. 2387-2397, 2006.

[237] M. S. Zhang, A. Sandouk, and J. C. Houtman, "Glycerol monolaurate (GML) inhibits human $\mathrm{T}$ cell signaling and function by disrupting lipid dynamics," Scientific Reports, vol. 6, p. 30225, 2016.

[238] K. L. Strandberg, M. L. Peterson, Y.-C. Lin, M. C. Pack, D. J. Chase, and P. M. Schlievert, "Glycerol monolaurate inhibits candida and Gardnerella vaginalis in vitro and in vivo but not lactobacillus," Antimicrobial Agents and Chemotherapy, vol. 54, no. 2, pp. 597-601, 2010.

[239] J. Sands, D. Auperin, and W. Snipes, "Extreme sensitivity of enveloped viruses, including herpes simplex, to long-chain unsaturated monoglycerides and alcohols," Antimicrobial Agents and Chemotherapy, vol. 15, no. 1, pp. 67-73, 1979.

[240] G. Bergsson, J. Arnfinnsson, S. M. Karlsson, O. Steingrimsson, and H. Thormar, "In vitro inactivation of chlamydia trachomatis by fatty acids and monoglycerides," Antimicrobial Agents and Chemotherapy, vol. 42, no. 9, pp. 2290-2294, 1998.

[241] G. Tachedjian, M. Aldunate, C. S. Bradshaw, and R. A. Cone, "The role of lactic acid production by probiotic lactobacillus species in vaginal health," Research in Microbiology, vol. 168, no. 9-10, pp. 782-792, 2017.

[242] M. Aldunate, D. Srbinovski, A. C. Hearps et al., "Antimicrobial and immune modulatory effects of lactic acid and short chain fatty acids produced by vaginal microbiota associated with eubiosis and bacterial vaginosis," Frontiers in Physiology, vol. 6, p. 164, 2015.

[243] J. Ravel, P. Gajer, Z. Abdo et al., "Vaginal microbiome of reproductive-age women," Proceedings of the National Academy of Sciences, vol. 108, no. 1, pp. 4680-4687, 2011.

[244] A. C. Hearps, D. Tyssen, D. Srbinovski et al., "Vaginal lactic acid elicits an anti-inflammatory response from human cervicovaginal epithelial cells and inhibits production of proinflammatory mediators associated with HIV acquisition," Mucosal Immunology, vol. 10, no. 6, pp. 1480-1490, 2017. 
[245] M. Aldunate, D. Tyssen, A. Johnson et al., "Vaginal concentrations of lactic acid potently inactivate HIV," Journal of Antimicrobial Chemotherapy, vol. 68, no. 9, pp. 2015-2025, 2013.

[246] D. Tyssen, Y. Y. Wang, J. A. Hayward et al., "Anti-HIV-1 activity of lactic acid in human cervicovaginal fluid," mSphere, vol. 3, 2018.

[247] W. p. Smith, "Epidermal and dermal effects of topical lactic acid," Journal of the American Academy of Dermatology, vol. 35, no. 3, pp. 388-391, 1996.

[248] T. Garg, M. Ramam, J. S. Pasricha, and K. K. Verma, "Long term topical application of lactic acid/lactate lotion as a preventive treatment for acne vulgaris," Indian Journal of Dermatology, Venereology and Leprology, vol. 68, pp. 137139, 2002.

[249] H. C. Huang, I. J. Lee, C. Huang, and T. M. Chang, "Lactic acid bacteria and lactic acid for skin health and to inhibit melanogenesis," Current Pharmaceutical Biotechnology, vol. 21, no. 7, 2020.

[250] K. E. Sharquie, S. M. Al-tammimy, S. Al-mashhadani, R. K. Hayani, and A. A. Al-nuaimy, "Lactic acid 5 percent mouthwash is an effective mode of therapy in treatment of recurrent aphthous ulcerations," Dermatology Online Journal, vol. 12, no. 7, p. 2, 2006.

[251] C. Van der veer, s. M. Bruisten, r. van Houdt et al., "Effects of an over-the-counter lactic-acid containing intra-vaginal douching product on the vaginal microbiota," $B M C M i$ crobiology, vol. 19, p. 168, 2019.

[252] F. G. Adeoshun, W. Ruppitsch, F. Allerberger, and F. A. Ayeni, "Prevalence and antimicrobial properties of lactic acid bacteria in nigerian women during the menstrual cycle," Polish Journal of Microbiology, vol. 68, no. 2, pp. 203-209, 2019.

[253] L. Armstrong-Buisseret, C. Brittain, M. David et al., "Metronidazole versus lactic acid for treating bacterial vaginosis (vita): protocol for a randomised controlled trial to assess the clinical and cost effectiveness of topical lactic acid gel for treating second and subsequent episodes of bacterial vaginosis," Trials, vol. 20, p. 648, 2019.

[254] C. R. Cohen, M. R. Wierzbicki, A. L. French et al., "Randomized trial of lactin- $\mathrm{V}$ to prevent recurrence of bacterial vaginosis," New England Journal of Medicine, vol. 382, no. 20, pp. 1906-1915, 2020.

[255] b. B. Aggarwal and B. Sung, "Pharmacological basis for the role of curcumin in chronic diseases: an age-old spice with modern targets," Trends in Pharmacological Sciences, vol. 30, no. 2, pp. 85-94, 2009.

[256] S. Z. Moghadamtousi, H. A. Kadir, P. Hassandarvish, h. Tajik, s. Abubakar, and k. Zandi, "A review on antibacterial, antiviral, and antifungal activity of curcumin," Biomed Research International, vol. 2014, p. 186864, 2014.

[257] S. C. Gupta, S. Patchva, and B. B. Aggarwal, "Therapeutic roles of curcumin: lessons learned from clinical trials," The AAPS Journal, vol. 15, no. 1, pp. 195-218, 2013.

[258] V. H. Ferreira, A. Nazli, S. E. Dizzell, K. Mueller, and C. Kaushic, "The anti-inflammatory activity of curcumin protects the genital mucosal epithelial barrier from disruption and blocks replication of HIV-1 and HSV-2," PLoS One, vol. 10, Article ID e0124903, 2015.

[259] A. Vlietinck, T. De Bruyne, S. Apers, and L. Pieters, "Plantderived leading compounds for chemotherapy of human immunodeficiency virus (HIV) infection," Planta Medica, vol. 64, no. 2, pp. 97-109, 1998.
[260] G. Schäfer and c. kaschula, "The immunomodulation and anti-inflammatory effects of garlic organosulfur compounds in cancer chemoprevention," Anti-Cancer Agents in Medicinal Chemistry, vol. 14, no. 2, pp. 233-240, 2014.

[261] R. Arreola, s. Quintero-Fabian, R. I. Lopez-Roa et al., "Immunomodulation and anti-inflammatory effects of garlic compounds," Journal of Immunology Reseach, vol. 2015, Article ID 401630, 2015.

[262] Y. Jeong, J. Ryu, J.-H. Shin et al., "Comparison of anti-oxidant and anti-inflammatory effects between fresh and aged black garlic extracts," Molecules, vol. 21, no. 4, p. 430, 2016.

[263] H. Kalant, "Medicinal use of cannabis: history and current status," Pain Research and Management, vol. 6, no. 2, pp. 80-91, 2001.

[264] M. R. Amin and D. W. Ali, "Pharmacology of medical cannabis," Advances in Experimental Medicine and Biology, vol. 1162, pp. 151-165, 2019.

[265] P. Sarzi-Puttini, A. Batticciotto, F. Atzeni et al., "Medical cannabis and cannabinoids in rheumatology: where are we now," Expert Review of Clinical Immunology, vol. 15, no. 10, pp. 1019-1032, 2019.

[266] R. Gallily, Z. Yekhtin, and L. O. Hanuš, "The anti-inflammatory properties of terpenoids from cannabis," Cannabis and Cannabinoid Research, vol. 3, no. 1, pp. 282-290, 2018.

[267] E. P. Baron, "Medicinal properties of cannabinoids, terpenes, and flavonoids in cannabis, and benefits in migraine, headache, and pain: an update on current evidence and cannabis science," Headache: The Journal of Head and Face Pain, vol. 58, no. 7, pp. 1139-1186, 2018.

[268] E. C. Mbvundula, k. D. Rainsford, and R. A. D. Bunning, "Cannabinoids in pain and inflammation," Inflammopharmacology, vol. 12, no. 2, pp. 99-114, 2004.

[269] K. Gyires and Z. Zádori, "Role of cannabinoids in gastrointestinal mucosal defense and inflammation," Current Neuropharmacology, vol. 14, no. 8, pp. 935-951, 2016.

[270] T. W. Klein, "Cannabinoid-based drugs as anti-inflammatory therapeutics," Nature Reviews Immunology, vol. 5, no. 5, pp. 400-411, 2005.

[271] M. D. Rizzo, R. B. Crawford, J. E. Henriquez et al., "HIVinfected cannabis users have lower circulating cd16+ monocytes and IFN-gamma-inducible protein 10 levels compared with nonusing HIV patients," AIDS, vol. 32, pp. 419-429, 2018.

[272] J. A. Manuzak, T. M. Gott, J. S. Kirkwood et al., "Heavy cannabis use associated with reduction in activated and inflammatory immune cell frequencies in antiretroviral therapy-treated human immunodeficiency virus-infected individuals," Clinical Infectious Diseases, vol. 66, no. 12, pp. 1872-1882, 2018. 